\title{
The Role of Collaboration, Computer Use, Learning Environments, and Supporting Strategies in CSCL
}

Citation for published version (APA):

Chen, J., Wang, M., Kirschner, P. A., \& Tsai, C-C. (2018). The Role of Collaboration, Computer Use, Learning Environments, and Supporting Strategies in CSCL: A Meta-Analysis. Review of Educational Research, 88(6), 799-843. https://doi.org/10.3102/0034654318791584

DOI:

10.3102/0034654318791584

Document status and date:

Published: 01/12/2018

Document Version:

Publisher's PDF, also known as Version of record

Document license:

Taverne

Please check the document version of this publication:

- A submitted manuscript is the version of the article upon submission and before peer-review. There can be important differences between the submitted version and the official published version of record. People interested in the research are advised to contact the author for the final version of the publication, or visit the DOI to the publisher's website.

- The final author version and the galley proof are versions of the publication after peer review.

- The final published version features the final layout of the paper including the volume, issue and page numbers.

Link to publication

\section{General rights}

Copyright and moral rights for the publications made accessible in the public portal are retained by the authors and/or other copyright owners and it is a condition of accessing publications that users recognise and abide by the legal requirements associated with these rights.

- Users may download and print one copy of any publication from the public portal for the purpose of private study or research.

- You may not further distribute the material or use it for any profit-making activity or commercial gain

- You may freely distribute the URL identifying the publication in the public portal.

If the publication is distributed under the terms of Article 25fa of the Dutch Copyright Act, indicated by the "Taverne" license above, please follow below link for the End User Agreement:

https://www.ou.nl/taverne-agreement

Take down policy

If you believe that this document breaches copyright please contact us at:

pure-support@ou.nl

providing details and we will investigate your claim.

Downloaded from https://research.ou.nl/ on date: 26 Apr. 2023 


\title{
The Role of Collaboration, Computer Use, Learning Environments, and Supporting Strategies in CSCL: A Meta-Analysis
}

\author{
Juanjuan Chen \\ Minhong Wang \\ The University of Hong Kong \\ Paul A. Kirschner \\ Open University of the Netherlands \\ University of Oulu, Finland \\ Chin-Chung Tsai \\ National Taiwan Normal University
}

\begin{abstract}
This meta-analysis synthesizes research findings on the effects of computer-supported collaborative learning (CSCL) based on its three main elements: (1) the collaboration per se, (2) the use of computers, and (3) the use of extra learning environments or tools, or supporting strategies in CSCL. In this analysis, 425 empirical studies published between 2000 and 2016 were extracted and coded, and these generated the following findings. First, the collaboration had significant positive effects on knowledge gain (ES [effect size] $=0.42)$, skill acquisition $(E S=0.64)$, and student perceptions $(E S=0.38)$ in computer-based learning conditions. Second, computer use led to positive effects on knowledge gain $(E S=0.45)$, skill acquisition $(E S=0.53)$, student perceptions $(E S=0.51)$, group task performance $(E S=0.89)$, and social interaction $(E S=0.57)$ in collaborative learning contexts. Third, the use of extra learning environments or tools produced a medium effect for knowledge gain $(E S=0.55)$, and supporting strategies resulted in an ES of 0.38 for knowledge gain. Several study features were analyzed as potential moderators.
\end{abstract}

KEYwords: computer-supported collaborative learning, CSCL, meta-analysis, learning environment or tool, supporting strategy 


\section{Chen et al.}

Collaborative learning (CL) draws on the theoretical framework of social constructivism learning theory and group or social cognition (Salomon \& Perkins, 1998; Stahl, 2006), and it emphasizes that knowledge is co-constructed through social interaction. It is a learning situation in which two or more students learn together to achieve a common goal or solve the task at hand, mostly through peerdirected interactions (Dillenbourg, 1999). In such learning situations, learners actively participate in group learning activities, while teachers usually serve as facilitators (P. A. Kirschner, 2001).

Computer-supported collaborative learning (CSCL) explores applying information and communication technologies (ICTs) to support CL, focusing on how technologies can facilitate group learning processes, knowledge sharing, and coconstruction (Kreijns, Kirschner, \& Jochems, 2003; Resta \& Laferrière, 2007; Stahl, Koschmann, \& Suthers, 2006). ICTs are increasingly transforming the way of teaching and learning by enabling learners to take active control of learning and interaction, facilitating knowledge sharing, and offering media for learning and communication without time or distance constraints (Kreijns et al., 2003; Stahl et al., 2006). CSCL may occur in campus-based classrooms (i.e., face-to-face $[\mathrm{FTF}]$ ), online or distance education (distributed synchronous or asynchronous), or blended learning settings (Resta \& Laferrière, 2007).

Many empirical studies have examined the effects of CSCL using multiple measures such as individual knowledge gain and skill acquisition, individual perceptions, group task performance, and social interaction. Moreover, CSCL is explored not as a distinct concept but as a learning situation involving multiple elements. Collaboration in learning processes and the use of computers to support CL are the two basic elements. In addition, CSCL studies typically embed more than one technology and/or involve supporting strategies, which constitute another element of CSCL.

\section{What Are the Main Elements of CSCL Examined in Empirical Studies?}

Some empirical studies have investigated the effects of collaboration in computer-supported learning settings. For example, Ke (2008) compared collaborative gameplay with individual gameplay in math learning, reporting that collaboration was effective in improving students' math attitudes but not in promoting math test performance. CL models can be learning together (e.g., Workman, 2004), small group or team learning (e.g., Ke, 2008), jigsaw (e.g., Moreno, 2009), dyadic learning (e.g., Kwon \& Cifuentes, 2009; Rebetez, Bétrancourt, Sangin, \& Dillenbourg, 2010), and so on.

Some studies have examined the effects of the use of computers in CL. Such studies generally compared the use of some kind of computer-based learning systems with paper-based learning settings. For example, Chen and Chen (2014) compared a digital reading annotation system (or e-book) with the paper-based reading annotation method and found that digital reading learners demonstrated better reading literacy and metacognitive skills (i.e., the use of reading strategies). The use of computers also involves other applications such as Moodle (e.g., Frailich, Kesner, \& Hofstein, 2009), Google Apps or Facebook (e.g., Genlott \& Grönlund, 2016; Roseth, Saltarelli, \& Glass, 2011), virtual reality or computer games (e.g., Hwang \& $\mathrm{Hu}, 2013)$, multitouch tablets (e.g., Mercier \& Higgins, 2013), and so on. 
Other studies have explored extra learning tools or strategies in CSCL contexts. It has been pointed out that placing learners together does not guarantee productive CL (Dillenbourg, 1999; Kreijns et al., 2003). Therefore, a variety of technology-mediated learning environments or tools (referring to learning platforms, systems, or tools) and strategies have been developed to support learners' engagement in productive interactions and in carrying out collaborative tasks. Studies on CSCL initially explored computer-mediated communication (CMC) such as discussion forums to promote group discussion (Fischer \& Mandl, 2005). Some extra discussion tools (e.g., videoconferencing) were then employed to enhance group discussion (e.g., Tsai, 2010). Moreover, visual representation tools (e.g., concept maps) were used to externalize complex ideas and maintain shared understanding (Janssen, Erkens, Kirschner, \& Kanselaar, 2010; Suthers, Vatrapu, Medina, Joseph, \& Dwyer, 2008; Wang, Cheng, Chen, Mercer, \& Kirschner, 2017), and group awareness tools were developed to monitor or coordinate collaborative activities (Janssen \& Bodemer, 2013). More recently, virtual environments (e.g., digital games, virtual reality, computer simulations), though not designed specifically for CL, have been deployed to promote conceptual learning, problem solving, and learners' engagement and motivation (Lin, Duh, Li, Wang, \& Tsai, 2013; Y. T. C. Yang, 2015). Furthermore, many other studies have explored a range of supporting strategies in CSCL, such as collaboration scripts (Dillenbourg \& Hong, 2008; Weinberger, Stegmann, \& Fischer, 2010), peer feedback (Xiao \& Lucking, 2008), and role assignment (Cheng, Wang, \& Mercer, 2014; Strijbos, Martens, Jochems, \& Broers, 2004). In short, the effects of CSCL are explored based on its three main elements - namely, (1) the collaboration per se, (2) the use of computers, and (3) the use of extra learning tools or strategies.

\section{What Are the Outcomes Measured in CSCL Studies?}

According to Pellegrino and Hilton (2013), the aims of learning are mainly directed at cognitive goals; motivational, affective, or intrapersonal goals; and social or interpersonal goals. They state that the cognitive goals are task and/or subject matter oriented (e.g., cognitive process, knowledge, skills); the motivational or affective goals include attitudes, beliefs, self-efficacy, and so on; and the social dimension includes peer interactions, teamwork, and so forth. The studies on CSCL have examined learning outcomes in alignment with these three goals.

First, the cognitive goals, such as individuals' knowledge improvement and/or acquisition of problem-solving skills, are the main goals of teaching and learning and are usually measured with objective tests. Second, the motivational or affective perceptions are important preconditions for CL and influence the quality of learning processes and persistence. The achievement of these goals is mainly subjectively measured by survey or questionnaire in the form of student perceptions. Finally, the achievement of social goals in CSCL mainly refers to the measurement of social interaction and activities among group members (Weinberger \& Fischer, 2006). The social interactions that group members engage in may be discussing and/or sharing task information, verbalizing ideas and opinions, making task-related plans, proposing problem solutions, and so forth (Janssen, Erkens, Kanselaar, \& Jaspers, 2007). Social interaction is necessary and important for 


\section{Chen et al.}

group members to reach shared understanding and to co-construct knowledge. Therefore, CSCL research has been more focused on learning processes over outcomes (Jeong, Hmelo-Silver, \& Yu, 2014). Different frameworks for the analysis of social interaction have been proposed and validated experimentally, such as the frameworks by Baker, Andriessen, Lund, Van Amelsvoort, and Quignard (2007), Janssen et al. (2007), and Weinberger and Fischer (2006). With these analysis frameworks, group discourse could be measured, which may generate reliable indicators for representing learning processes in CSCL environments (Weinberger \& Fischer, 2006).

The literature shows that the effects of CSCL have been examined in multiple measures mainly including individual knowledge gains, individual skill acquisition, individual perceptions, group task performance, and social interaction. Many studies have reported favorable effects of CSCL on learning outcomes. For example, Sung and Hwang (2013) found that collaborative game-based learning improved students' academic achievement, and learning attitudes and motivation. Noroozi, Biemans, Weinberger, Mulder, and Chizari (2013) found that collaboration scripts greatly fostered learners' skills, group task performance, and social interactions. However, some others found quite different results. For example, Roseth et al. (2011) compared the learning outcomes of CSCL with those of CL without computer use, with the results favoring the latter.

To synthesize the various findings of the different studies, meta-analysis is useful for analyzing a collection of empirical studies to produce quantitative findings (Cooper, Hedges, \& Valentine, 2009). It examines the same constructs and relationships (generally causal relationships). The main output of a meta-analysis is the effect size $(E S)$, which is defined as the mean difference between the experimental and control groups divided by the pooled standard deviation and standardizes findings across studies so that they can be directly compared (Lipsey \& Wilson, 2001). Meta-analysis focuses on the direction and magnitude of the effects across studies. The direction (i.e., positive or negative effect) can be seen from the sign or confidence interval, and the magnitude can be seen from the value of $E S$, with 0.20 to 0.49 being considered as small effects, 0.50 to 0.79 as moderate effects, and 0.80 or higher as large effects (Cohen, 1992). According to Slavin, Lake, and Groff (2009), an ES of 0.20 can be considered to be substantively important for practice.

\section{Prior Meta-Analyses}

There have been a few meta-analyses on collaborative or cooperative learning that mostly synthesized the impacts of traditional CL without computer use, such as Springer, Stanne, and Donovan (1999) and Kyndt et al. (2013). These metaanalyses combined the results of studies that compared CL with individualistic learning in FTF settings without computer use and concluded with positive ESs for learners' achievements and attitudes. Note that collaborative learning and cooperative learning, though not the same, are used interchangeably. Some studies titled "cooperative learning" were actually on collaborative learning. For example, in Moreno (2009), meaning and solution were negotiated and agreed on among group members, which are typical collaborative activities. 
There have also been reviews investigating technology support in CL, but they were limited in terms of the time span of the empirical studies, the databases that were searched, the subject areas, educational levels, and the technology types. Lou, Abrami, and D'Apollonia (2001) synthesized 122 studies from 1965 to 1999, focusing on the effects of small group learning with technology versus individual learning with technology. They reported a small $E S$ of 0.15 for individual achievement and significant positive attitudes toward classmates $(E S=0.29)$ but no significant positive attitudes toward computers $(E S=0.02)$, subject or instruction $(E S=0.07)$, or academic self-concept $(E S=0.04)$.

The meta-analysis by Borokhovski, Bernard, Tamim, Schmid, and Sokolovskaya (2016) integrated the results of 25 studies contrasting CSCL with alternative instructional methods (i.e., individual learning, or CL with little technology involved) in postsecondary classroom settings. Studies on distance education environments were excluded because the authors only analyzed FTF learning contexts. The ES for achievement was 0.52 . Nevertheless, this synthesis did not distinguish between the roles of CL, computer use, or some extra tools.

Similarly, the issue of not distinguishing between the roles of the three main elements of CSCL also exists in the meta-analysis by Jeong, Hmelo-Silver, Jo, and Shin (2016). Jeong and colleagues synthesized the effects of CSCL in STEM (science, technology, engineering, and mathematics) education by combining the findings of 80 studies published in seven major journals, and found an ES of 0.53. Another issue with their meta-analysis is that when calculating $E S$, they did not distinguish between knowledge achievement, affective outcome, and process performance, but just combined them all. This is inconsistent with the rule of independent studies in meta-analysis (Lipsey \& Wilson, 2001). In addition, studies only reporting students' perceptions or group processes without academic achievement were included, whereby perceived learning and actual learning were confounded. Moreover, the results from only seven journals may lead to biased ESs as they fail to capture a diverse range of literature.

Others have focused on a particular computer learning tool or supporting strategy employed in CSCL. For example, the meta-analysis by Wecker and Fischer (2014) investigated the impacts of argumentation interventions (e.g., collaboration scripts, argument visualization tools) and found a small ES of 0.39 for argumentation skill and 0.00 for domain-specific knowledge. More specifically, they found that collaboration scripts led to a statistically significant $E S$ of 0.91 for argumentation and a nonsignificant $E S$ of 0.12 (with a $90 \%$ confidence interval including 0) for domain-specific knowledge; argument visualization tools resulted in a nonsignificant $E S$ of 0.17 for argumentation, and a negative $E S$ of -0.56 for domain-specific knowledge. Similarly, Vogel, Wecker, Kollar, and Fischer (2017) examined the effects of using collaboration scripts as a group interaction-supporting strategy and reported a small $E S$ of 0.20 for domain-specific knowledge and a large positive $E S$ of 0.95 for argumentation skill when compared with collaboration without scripts.

\section{Purpose of This Study}

The present study conducted a comprehensive meta-analysis of the effects of CSCL for the following reasons. First, when discussing the effects of CSCL, 


\section{Chen et al.}

education researchers and practitioners need to know where the effects come from. Given that the effects of CSCL can be attributed to its different yet interrelated elements - namely, CL, computer use, the use of extra technology-mediated learning environments or tools, or supporting strategies in the CSCL context, it is important to gain a deeper understanding of the distinct roles of these elements, thus requiring their differentiation. Second, there is a great need to know whether the effects of CL versus individual learning supported by computers are consistent with the findings reported by Lou et al. (2001) due to the explosion in the use of computers in the classroom in the past decade. On the other hand, students have more frequent access to ICTs nowadays than they did 20 years ago and are thus better acquainted with using computers in their learning. Third, there have been few reviews investigating the effects of computer use, while inconsistent results and findings have been reported by studies comparing CSCL and traditional CL. Fourth, while the effects of CSCL may vary greatly with different technological tools or supporting strategies, there has been no meta-analysis of their integral effects as existing reviews only synthesize a specific tool or strategy. Researchers and practitioners need to know what the comparative effects of different approaches are.

This research reports on a meta-analytical integration of the effects of CSCL based on its three different elements: (1) CL (i.e., CL vs. non-CL or individual learning, both with computer support), (2) computer use (i.e., with vs. without computer use, in CL settings), and (3) the use of extra technology-mediated learning environments or tools, or supporting strategies (i.e., with vs. without specific learning environments or tools, or supporting strategies, in the CSCL contexts). In analyzing each element, the effects on learning outcomes and learning processes are examined. This synthesis may inform education researchers and practitioners regarding how CSCL can improve learning in different ways.

\section{Research Questions}

Research Question 1: What are the effects of CL versus non-CL (i.e., individual learning) in computer-supported settings on students' knowledge gain, skill acquisition, and perceptions?

Research Question 2: What are the effects of computer use versus no computer use in CL settings on students' knowledge gain, skill acquisition, perceptions, group task performance, and social interaction?

Research Question 3: What are the effects of the use of extra technologymediated learning environments or tools, or supporting strategies in CSCL on students' knowledge gain, skill acquisition, perceptions, group task performance, and social interaction compared with not adopting them?

Beyond the three research questions, the present study analyzed some potential moderators identified from previous meta-analyses on this topic, such as research design, sample size, and intervention duration, as they might contribute to the variance in ESs. The moderator analyses explored the relationships between these features and learning outcomes. 


\section{Method \\ Literature Search}

The studies used were located through a comprehensive literature search of the Web of Science online database using the following search terms: ("Collaborative learning" OR "Cooperative learning" OR "Group* learning" OR "Team* learning" OR "CSCL*") AND ("Computer*" OR "Online*" OR "Web*" OR "Internet*" OR "Network*" OR "Technolog*" OR "Mobile*" OR "Virtual*" OR "Simulat*" OR "Game*") at 11:10 a.m., December 17, 2016. The search terms needed to appear in the title, abstract, or keywords of the document. The Timespan was defined as 2000 to 2016, Document Type as Article, and Language as English. The choice of the search terms was based on the concepts in CSCL-namely, learning, collaboration, and computer support, and we also consulted previous literature (Noroozi, Weinberger, Biemans, Mulder, \& Chizari, 2012). The reason for adding the latter four additional key words is that they represent typical technology-mediated CSCL environments (authors may use these words instead of "computer" or "technology" in their papers). The reason for the database choice is that the Web of Science is a typical database used by previous meta-analyses published in this journal such as those by Clark, Tanner-Smith, and Killingsworth (2016) and Nesbit and Adesope (2006). In total, the search of the Web of Science yielded 3,226 articles. Additionally, we searched Google Scholar on January 15, 2017, using seven separate searches (including computer supported collaborative learning, computer-supported collaborative learning, CSCL, collaborative learning, cooperative learning, group learning, and team learning). We searched the first 300 most frequently cited articles appearing in every Google Scholar search output for the seven searches (2,100 in total) and removed overlapping articles with the search output of the Web of Science, thus yielding an additional 274 articles. There was therefore a total of 3,500 articles (combining the 3,226 results from the Web of Science and the 274 results from Google Scholar), which then underwent a further filtering process. In fact, the search output from Google Scholar showed that most of the articles on CSCL studies had been included in the Web of Science online database. All articles were further filtered based on the following inclusion/exclusion criteria.

\section{Inclusion and Exclusion Criteria}

To be included, a study had to meet all of the following criteria:

1. The research must be an empirical study. Empirical means that the study collects and analyzes empirical data; thus, secondary data analyses, meta-analyses, theoretical papers, and simulated results (from simulation models) were excluded.

2. The research must use a controlled experimental or quasi-experimental design, which means that it employed CSCL for experimental groups and compared it with an alternative learning method for control groups (e.g., computer-supported individual learning, $\mathrm{CL}$ without computer use). The control groups must involve participants independent of the experimental 
groups, so studies including only a single group (i.e., pre-post comparisons) were excluded.

3. The study must use a pretest or other prior variable correlated with learning outcomes to ensure the equivalence of the experimental and control groups before the experiment was conducted. Studies that reported a pretest $E S$ beyond the range $-0.40<E S<0.40$ were excluded, because a difference of this magnitude is too large to be adjusted by covariance analysis.

4. The learning content must be taught equally in both the experimental and control conditions. That is, the use of achievement measures was independent of the experimental treatment.

5. The research had to present quantitatively measured achievement outcomes at either the individual or group level for both the experimental and control conditions. Achievement outcomes can be knowledge test scores, individual learning skills, or group task performance. If the control condition is computer-supported individual learning, then the study must report individual-level student test score or skill.

6. The results must provide sufficient data for calculation of ES of an intervention, including means and standard deviations/errors ( $S D$ or $S E$ ), F ratio of $F$ test, $t$ value of $t$ test, chi-square statistics, $r$-index, or $z$ score of Mann-Whitney's $U$ test, as well as the number of participants in the experimental and control groups. For 15 articles with insufficient information for calculation of $E S$ (e.g., with means but without $S D$ ), we contacted the authors and got 11 replies. Of those, seven had either deleted the raw data or had no access to the data; thus only four were included.

7. Studies on gifted education, special education, or disabilities learning were excluded. Ten such articles were found.

Note that there was another criterion for exclusion. The same study (with the same sets of data) published in different journals was counted as one study. For example, Tsai (2010) is the same as Tsai (2013).

Two of the researchers of this study first independently reviewed the first one third of the 3,500 search results and reached an agreement of .82, after which they discussed and resolved any conflicts that arose. After that, the first author reviewed the remaining articles, but regularly met with the second author to discuss uncertainty in selection and filtering, and arrived at consensus, with a final agreement rate of .85 for all articles. The two authors also discussed and reached agreement on the coding framework, which was sent to the other authors who confirmed it. Among the excluded articles, 1,030 of 3,500 (29.4\%) articles were not CSCL empirical studies, 1,010 (28.9\%) did not employ a control group, and others only reported results on students' perceptions or social interaction, or were case studies, reports of software development, and so forth. Six duplicates were also removed.

\section{Coding Framework}

The purpose of coding is to describe and differentiate selected studies, extract findings, and further identify substantive features that may contribute to 
the variance in ESs. The coding framework used in this study was built on the theoretical frameworks from previous literature (P. A. Kirschner \& Erkens, 2013; Lou et al., 2001; Noroozi et al., 2012).

\section{Substantive Study Features}

For each selected study, data were extracted for the following study features: educational level, subject area, number of participants in both experimental and control conditions, research design (experimental or quasi-experimental), treatment duration, outcomes (e.g., individual academic achievement, interaction process), type of test (e.g., standardized test like national or state test, locally developed test aligned with the learning objectives of the experiment), and intervention or treatment (i.e., experimental condition and control condition being contrasted).

\section{Learning outcomes and processes}

Table 1 describes the details of the outcomes extracted from the studies, including individual academic achievement, perceptions, group task performance, and learning process, which are typical variables extracted in previous CSCL syntheses such as Lou et al. (2001). Academic achievement is the knowledge and skills that an individual acquires through direct teaching and learning. The term perceptions refers to self-evaluations measured by survey or questionnaire, such as learning attitude, motivation, satisfaction, interest, and so on (Kyndt et al., 2013). Learning process in CL mainly refers to social interaction and activities among group members, typically measured by computer log data, text messages, or video transcripts (Jeong et al., 2014; Weinberger \& Fischer, 2006). Social interaction may occur FTF or remotely via CMC.

\section{Control conditions}

The selected studies vary considerably according to the nature of the control conditions in the experimental design. Regarding the control conditions, the studies were coded into four categories. Category 1 (corresponding to Research Question 1) examined the effects of collaboration in computer-based learning settings (i.e., collaborative vs. individual learning, both with computer support). Category 2 (corresponding to Research Question 2) examined the effects of computer use in CL settings (i.e., with vs. without computer use). Category 3 (corresponding to Research Question 3) examined the effects of the use of extra learning environments or tools, or supporting strategies under the condition of CSCL (i.e., with vs. without extra technology environments or tools, or strategies). The studies in Category 4 involved a comparison between different learning environments or tools, or supporting strategies. For example, Fischer and Mandl (2005) compared a content-specific representation tool with a contentindependent representation tool. One selected paper may report several studies and thus can be assigned to multiple categories. For example, Corter, Esche, Chassapis, Ma, and Nickerson (2011) was coded into Categories 1, 2, and 3. As the comparisons in Category 4 did not have much in common or the number of samples in each similar comparison was less than five, Category 4 was not further analyzed. 


\section{TABLE 1}

Outcomes analyzed in this meta-analysis

\begin{tabular}{|c|c|}
\hline Outcomes & Description \\
\hline \multicolumn{2}{|l|}{ Individual level } \\
\hline $\begin{array}{l}\text { Knowledge } \\
\text { gain }\end{array}$ & $\begin{array}{l}\text { Subject matter knowledge improvement, measured by individually } \\
\text { administered immediate posttest or final course examination, which } \\
\text { are standardized knowledge tests or tests locally developed by } \\
\text { teachers, instructors, or researchers. }\end{array}$ \\
\hline $\begin{array}{l}\text { Skill } \\
\text { acquisition }\end{array}$ & $\begin{array}{l}\text { Thinking skills (e.g., higher order thinking skills, critical thinking } \\
\text { skills), problem-solving skills (e.g., programming), or group learning } \\
\text { skills, measured by objective tests. }\end{array}$ \\
\hline \multirow[t]{10}{*}{ Perception } & Measured by survey or questionnaire. \\
\hline & $\begin{array}{l}\text { 1. Evaluation of the overall course, learning system, or learning } \\
\text { environment (e.g., usefulness, ease of use, satisfaction, intention to } \\
\text { use learning system or environment) }\end{array}$ \\
\hline & $\begin{array}{l}\text { 2. Perception or evaluation of specific learning approach or technique } \\
\text { (e.g., perceptions of the collaborative learning approach, concept- } \\
\text { mapping technology, intention to use) }\end{array}$ \\
\hline & 3. Overall learning experience (e.g., enjoyment, engagement) \\
\hline & $\begin{array}{l}\text { 4. Attitude toward a specific discipline (e.g., attitude toward science, } \\
\text { motivation to learn science, interest) }\end{array}$ \\
\hline & $\begin{array}{l}\text { 5. Perceived capability (e.g., competency, academic self-efficacy, or } \\
\text { self-concept) }\end{array}$ \\
\hline & $\begin{array}{l}\text { 6. Perceived performance in specific skills (e.g., problem solving, use } \\
\text { of technologies, confidence in clinical management, social efficacy) }\end{array}$ \\
\hline & 7. Perceived individual learning gains (e.g., perceived learning) \\
\hline & 8. Perceived group learning outcome \\
\hline & 9. Perceived group process (e.g., social presence, cooperativeness) \\
\hline \multicolumn{2}{|l|}{ Group level } \\
\hline $\begin{array}{l}\text { Group task } \\
\text { performance }\end{array}$ & $\begin{array}{l}\text { Measured by group report, essay, assignment, problem solutions, } \\
\text { other group artifacts (e.g., story, concept map), or the accuracy of } \\
\text { completed subtasks, assessed at the group level. (Note that when the } \\
\text { control condition was computer-supported individual learning, group } \\
\text { task performance and social interaction were not included in the } \\
\text { analysis.) }\end{array}$ \\
\hline $\begin{array}{l}\text { Social } \\
\quad \text { interaction }\end{array}$ & $\begin{array}{l}\text { Task-related (e.g., argumentation, knowledge construction, } \\
\text { metacognitive activities), social activities (e.g., greeting), off-task } \\
\text { (e.g., technical, nonsense). Measured by quantitative process analysis } \\
\text { or content analysis of discourse. (Note that if only the total number } \\
\text { of discussion posts was reported without detailed categorization of } \\
\text { discussion, effect size was not calculated for such interaction results.) }\end{array}$ \\
\hline
\end{tabular}

\section{Using Extra Technology-Mediated Learning Environments or Tools}

The studies in Category 3 vary greatly in terms of the type of interventions employed (i.e., specific environments or tools, or supporting strategies). Therefore, 
a framework was adopted to put them into either learning environment, tool, or supporting strategy subcategories, and then they were further categorized based on their main functions. The categorization was built on the theoretical framework of Dillenbourg (1999) and P. A. Kirschner and Erkens (2013).

Learning environments or tools mainly refer to learning platforms, systems, or tools (e.g., videoconferencing systems, online forums). In this meta-analysis, there are seven major subcategories: (1) Basic Online Discussion, (2) Enhanced Online Discussion, (3) Visual Representation Tools, (4) Group Awareness Tools, (5) Graphs or Multimedia for Instruction, (6) Adaptive or Intelligent Systems, and (7) Virtual Environments. Although one environment or tool may involve several technologies, we tried to differentiate them on the basis of their main functions or intentions. For example, a computer-based concept mapping tool also provides a text chat function, but its main function is visual representation of knowledge structure. The categorization process also referred to the keywords listed in each article, which explicitly indicated the main functions of the tools or strategies used in that study. Table 2 shows the detailed description and examples of the learning environments or tools in each of the seven subgroups. Some screenshots of these tools' interfaces could be found in the Supplemental Material titled "Interface Examples of the Learning Tools" (available in the online version of the journal)

Other subgroups of learning environments or tools include annotation tools (e.g., Su, Yang, Hwang, \& Zhang, 2010) and multitouch interactive tabletops (e.g., Hsiao, Chang, Lin, Chang, \& Chen, 2014). As there were $<5$ samples in each of these subgroups, they were not analyzed in this study.

\section{Online discussion (basic and enhanced)}

Basic Online Discussion (i.e., forums) is implemented in the experimental condition, while students in the control condition perform CSCL FTF. Enhanced Online Discussion refers to the situation in which some extra electronic communication tools are provided for learners in the experimental condition, though learners in both the experimental and control conditions use the same learning platform. For example, in one experimental study, Roseth et al. (2011) compared synchronous with asynchronous video discussion; here, synchronous video is considered as Enhanced Online Discussion. Such extra electronic communication tools are intentionally used in CL so as to promote discussion between group members in distributed locations.

\section{Visual representation tools}

Visual Representation Tools refer to tools that allow learners to construct representations such as concept maps. Visual representations enable learners to explicitly externalize complex ideas and the relationships between those ideas. They are expected to help students organize concepts or ideas and engage them in higher order thinking (Chen, Wang, Grotzer, \& Dede, 2018; Gijlers \& de Jong, 2013; Janssen et al., 2010; Sung \& Hwang, 2013; Wu \& Wang, 2012). Visual representations serve as a common ground or shared understanding to facilitate group discussion and address the issues of coherence and convergence. For example, 
TABLE 2

Learning environments or tools and supporting strategies analyzed in this meta-analysis

\begin{tabular}{|c|c|c|}
\hline Tool or strategy & Description & Examples \\
\hline \multicolumn{3}{|c|}{ Learning environment or tool } \\
\hline $\begin{array}{c}\text { Basic Online } \\
\text { Discussion }\end{array}$ & $\begin{array}{l}\text { CSCL is performed in both } \\
\text { experimental and control } \\
\text { conditions. Students in the } \\
\text { control condition communicate } \\
\text { face-to-face, while their } \\
\text { counterparts communicate } \\
\text { through computers. }\end{array}$ & $\begin{array}{l}\text { Asynchronous discussion } \\
\text { board or forum, textual } \\
\text { chat tool, online learning } \\
\text { community }\end{array}$ \\
\hline $\begin{array}{l}\text { Enhanced Online } \\
\text { Discussion }\end{array}$ & $\begin{array}{l}\text { Computer-mediated } \\
\text { communication is implemented } \\
\text { in both the experimental and } \\
\text { control conditions; however, } \\
\text { some extra communication tools } \\
\text { are provided for learners in the } \\
\text { experimental condition. }\end{array}$ & $\begin{array}{l}\text { Synchronous } \\
\text { videoconferencing, } \\
\text { speech recognition } \\
\text { tool (for synchronous } \\
\text { communication), threaded } \\
\text { discussion tool, Skype, } \\
\text { Twitter for communication }\end{array}$ \\
\hline $\begin{array}{l}\text { Visual } \\
\text { Representation } \\
\text { Tools }\end{array}$ & $\begin{array}{l}\text { Learners construct representations } \\
\text { that visualize the conceptual } \\
\text { ideas and serve as a common } \\
\text { ground or shared understanding. }\end{array}$ & $\begin{array}{l}\text { Concept map, mind map, } \\
\text { knowledge map, knowledge } \\
\text { modeling, diagram, list, } \\
\text { matrix, outline, external } \\
\text { representation }\end{array}$ \\
\hline $\begin{array}{l}\text { Group Awareness } \\
\text { Tools }\end{array}$ & $\begin{array}{l}\text { Monitor or visualize group } \\
\text { activities/interactions or provide } \\
\text { cues about members' knowledge } \\
\text { level. }\end{array}$ & $\begin{array}{l}\text { Participation tool, social } \\
\text { awareness tool, group } \\
\text { knowledge awareness tool }\end{array}$ \\
\hline $\begin{array}{l}\text { Graphs or } \\
\text { Multimedia for } \\
\text { Instruction }\end{array}$ & $\begin{array}{l}\text { Prebuilt and provided by } \\
\text { instructors or teachers for } \\
\text { learners' observation. }\end{array}$ & $\begin{array}{l}\text { Graph, multimedia, animated } \\
\text { multimedia }\end{array}$ \\
\hline $\begin{array}{l}\text { Adaptive or } \\
\text { Intelligent } \\
\text { Systems }\end{array}$ & $\begin{array}{l}\text { Provide adaptive and intelligent } \\
\text { assistance for learning groups. }\end{array}$ & $\begin{array}{l}\text { Adaptive intelligence } \\
\text { learning system, } \\
\text { recommender system }\end{array}$ \\
\hline $\begin{array}{l}\text { Virtual } \\
\text { Environments }\end{array}$ & $\begin{array}{l}\text { Interactive or immersive learning } \\
\text { environments, which simulate } \\
\text { real-world situations and offer } \\
\text { interactions. }\end{array}$ & $\begin{array}{l}\text { Digital game, simulation, } \\
\text { augmented reality, virtual } \\
\text { reality, second life }\end{array}$ \\
\hline \multicolumn{3}{|l|}{ Supporting strategy } \\
\hline $\begin{array}{l}\text { Teacher's } \\
\text { Facilitation }\end{array}$ & $\begin{array}{l}\text { Teachers provide supports and } \\
\text { guidance on the collaboration } \\
\text { process by using cognitive and } \\
\text { affective strategies. }\end{array}$ & $\begin{array}{l}\text { Teacher explanation and } \\
\text { modeling, teacher initiation } \\
\text { and feedback, behavior } \\
\text { modeling }\end{array}$ \\
\hline $\begin{array}{l}\text { Peer Feedback or } \\
\text { Assessment }\end{array}$ & $\begin{array}{l}\text { Learners give and/or receive } \\
\text { feedback or reviews on one } \\
\text { another's performance. }\end{array}$ & $\begin{array}{l}\text { Peer feedback, peer } \\
\text { monitoring, peer } \\
\text { assessment, peer review }\end{array}$ \\
\hline
\end{tabular}


TABLE 2 (continued)

\begin{tabular}{|c|c|c|}
\hline Tool or strategy & Description & Examples \\
\hline Role Assignment & $\begin{array}{l}\text { Each group member is assigned } \\
\text { a specific functional role, } \\
\text { being accountable for the task } \\
\text { completion. }\end{array}$ & Functional role or leader \\
\hline $\begin{array}{l}\text { Instruction and } \\
\text { Guidance } \\
\text { (mainly via } \\
\text { scripts) }\end{array}$ & $\begin{array}{l}\text { Help sustain group discourse } \\
\text { and promote students' social } \\
\text { interaction by providing } \\
\text { guidance on initiating a } \\
\text { discussion topic, continuing their } \\
\text { group discourse, or reaching } \\
\text { consensus. }\end{array}$ & $\begin{array}{l}\text { Dynamic collaboration script, } \\
\text { discussion script, social } \\
\text { script, epistemic script, } \\
\text { advice, instruction on } \\
\text { effective communication }\end{array}$ \\
\hline
\end{tabular}

Janssen et al. (2010) asked students in the experimental conditions to co-construct diagrams to promote their argumentation and reasoning.

\section{Group awareness tools}

Group awareness refers to perception and information of various aspects of a group (Buder \& Bodemer, 2008). In remote computer-mediated learning scenarios, to communicate efficiently and engage in co-construction of knowledge, group members have to know what is happening in the group and how much their peers understand. If members' knowledge substantially overlaps, there is no need to deeply discuss the underlying concept. If one peer knows what others do not know, more elaboration and negotiation may be needed. Group Awareness Tools aim at visualizing group activities and interactions (e.g., ratings on contributions in a discussion forum; Janssen et al., 2007) or providing learners with cues about their peers' level of knowledge (Janssen \& Bodemer, 2013). Examples include PT (participation tool; Janssen et al., 2007) and GKA (group knowledge awareness; Dehler, Bodemer, Buder, \& Hesse, 2011).

\section{Graphs or multimedia for instruction}

Graphs or Multimedia for Instruction include representations that have been prebuilt and are provided by instructors or teachers. Rebetez et al. (2010) defined multimedia instruction as a kind of instruction incorporating both symbolic (e.g., text, formula) and nonverbal information (e.g., graphics, schemas). Graphs or Multimedia are mainly provided for learners to observe, without interacting with the system (e.g., drawing or editing graph). For example, Rebetez et al. (2010) used both static graphics and dynamic animations to explain how natural or artificial dynamic systems work.

\section{Adaptive or intelligent systems}

Computer-supported learning not only makes learning resources available to learners but also supports personalized learning processes (Hoic-Bozic, Holenko 


\section{Chen et al.}

Dlab, \& Mornar, 2016). Such functions apply to both individual learning and CL. Personalization can be achieved by adaptive hypermedia and recommender systems (Brusilovsky \& Henze, 2007; Manouselis, Drachsler, Vuorikari, Hummel, \& Koper, 2011; Wang, Yuan, Kirschner, Kushniruk, \& Peng, 2018), which enable users to access learning resources relevant to their interests, knowledge level, or activity level. Examples include ANTS (the Agent-based Navigational Training System; Huang \& Liu, 2009) and the ELARS recommender system (Hoic-Bozic et al., 2016).

\section{Virtual environments}

Virtual Environments simulate real-world situations and offer real-time interaction (Dede, 2009; Hale \& Stanney, 2014). Examples include augmented reality (which combines virtual and real-world scenarios) or virtual reality (e.g., Lin et al., 2013), and digital games and/or simulations (e.g., Y. T. C. Yang, 2015). In digital game-based learning, learners often become more engaged or immersed in the learning activities by way of the virtual role playing. Computer simulations attempt to model a real-life or hypothetical situation with a computer system so that the learner can observe causal relationships among variables (Corter et al., 2011). Virtual Environments are mainly used to support situated learning, provide learners with authentic learning experience, foster higher order thinking skills, and improve their motivation and concentration.

\section{Using Extra Supporting Strategies}

Supporting strategies are specific group learning strategies used in the experimental condition to promote group performance. While the learning environments or tools have afforded significant opportunities for CL, the technology itself does not guarantee effective learning in collaborative contexts (Kreijns et al., 2003). Therefore, many studies have explored possible strategies to promote collaboration in CSCL, as reflected in the meta-analysis by Vogel et al. (2017). The supporting strategies used as the main interventions were coded into the following four major subgroups: Teacher's Facilitation, Peer Assessment or Peer Feedback, Role Assignment, and Instruction and Guidance (mainly via scripts). Table 2 provides detailed descriptions and examples of the supporting strategies in each of the four subgroups.

Other subgroups of supporting strategy include peer tutoring (e.g., Okita, Turkay, Kim, \& Murai, 2013), intragroup competition (e.g., Yu, 2001), rewards (e.g., Brewer \& Klein, 2006), and so on. They were not further analyzed in this study as there were fewer than five samples in these subgroups.

\section{Teachers' facilitation}

In CSCL, the role of the instructor or teacher shifts from knowledge expert to facilitator, the primary role of which is to support and guide the collaboration process (Hsieh \& Tsai, 2012; Michinov \& Primois, 2005). Teachers' Facilitation helps students articulate important ideas and engage in more meaningful interactions. Their facilitative strategies can be classified into two primary dimensions: cognitive and affective strategies. The cognitive strategy is to promote students' 
knowledge construction by making them focus on the learning task or topic and enhance their argumentation. The affective strategy is to improve students' motivation by giving positive feedback and helping sustain deep discourse.

\section{Peer feedback or peer assessment}

In learning situations, feedback is defined as the information on learners' performance provided by others such as teachers, computers, and/or peers (Hattie \& Timperley, 2007). Peer Feedback refers to feedback from fellows of the same status. Learners take the role of both the assessor and the assessee. As assessors, they need to recognize particular evaluation criteria, judge the performance of peers, and provide feedback. Assessees need to review the feedback provided by peers, decide on the changes necessary to improve their work, and proceed to make the changes (Hovardas, Tsivitanidou, \& Zacharia, 2014). These activities can make learners have a better understanding of the subject matter, develop critical thinking skills, enhance their writing skills, and improve their learning motivation (Trautmann, 2009; Xiao \& Lucking, 2008).

\section{Role assignment}

This is a strategy of structuring collaborative activities in group learning (Morris et al., 2010; Strijbos et al., 2004). According to Hare (1994), roles can be defined as stated or prescribed responsibilities or duties guiding individual behavior and regulating collaboration. Each designated role may assume a type of task completion function, such as data collector, data analyzer, leader, or coordinator, generally assigned by the researcher or instructor.

\section{Instruction and guidance}

This mainly refers to scaffolding to promote students' social interaction and specific discourse skills, such as questioning, arguing, and explaining (Vogel et al., 2017). Students may have difficulties initiating a discussion topic, continuing their group discourse, or reaching consensus, especially in distributed CL settings, which may result in off-task behaviors or superficial discussions without deep reflection. Collaboration scripts, message starters, and message prompts or hints are commonly used interventions or guidance about how to interact effectively (Kollar, Fischer, \& Hesse, 2006; Vogel et al., 2017). They are usually embedded in text-based discussion forums and have been developed to help students overcome these difficulties and enhance their collaboration.

\section{Statistical Methods}

\section{Calculation of ES for Each Separate Study}

$E S$ allows for comparison of effectiveness of treatments across studies (Lipsey $\&$ Wilson, 2001). Cohen's $d$ and Hedges's $g$ are the two most frequently used indices of ES. Cohen's $d$ usually uses the standardized mean difference between the experimental and control conditions divided by the pooled standard deviation $(S D)$ and is commonly represented by Formula 1. 
Chen et al.

$$
d=\frac{\bar{X}_{\text {Experimental }}-\bar{X}_{\text {Control }}}{S D_{\text {Pooled }}}
$$

where $\bar{X}$ represents the mean score when only posttest data are reported or the gain score when both pre- and posttest scores are available (meaning posttest minus pretest scores) for the variables of interest (e.g., knowledge gain, perceptions), and $S D_{\text {Pooled }}$ is the pooled standard deviation, which is calculated by Formula 2.

$$
S D_{\text {Pooled }}=\sqrt{\frac{S_{1}^{2}\left(n_{1}-1\right)+S_{2}^{2}\left(n_{2}-1\right)}{n_{1}+n_{2}-2}}
$$

where $S_{1}^{2}$ and $S_{2}^{2}$ represent the posttest standard deviation of the experimental and control conditions, respectively, and $n_{1}$ and $n_{2}$ are the number of participants in both conditions, respectively.

The effect size $d$ is positive if the experimental group performs better than the control group, and vice versa. It would have upward bias when the sample size is small. To remove the small-sample size bias, Cohen's $d$ was converted to Hedges's $g$ using Formula 3. Hedges's $g$ tends to result in a slightly smaller ES.

$$
g=d\left(1-\frac{3}{4\left(n_{1}+n_{2}\right)-9}\right)
$$

When the raw data in one study were in the forms of $t$ test, $F$ test, $r$ index, or chi-square values, the effect size $d$ was computed via algebraically equivalent formulas provided by Lipsey and Wilson (2001) or a Web-based ES convertor developed by them.

For studies with multiple measures of one outcome or more than one experimental or control condition, the following rules were applied to the calculation of ES:

- When multiple measurements of one outcome were reported (e.g., posttest and final exam for knowledge achievement), their effect sizes were averaged. This guarantees that there was only one $E S$ for each outcome in each study, ensuring the independence of extracted ESs. ESs derived from separate participants are considered statistically independent, while those obtained from overlapping participant samples are considered statistically dependent (Lipsey \& Wilson, 2001).

- When there was more than one experimental condition and only one single control condition, or there was more than one control condition and only one experimental condition, dependent ESs for each comparison were averaged weighting mainly by sample size (Tanner-Smith \& Tipton, 2014).

- When there were two or more experimental conditions and two or more control conditions, one $E S$ was extracted for each intervention. As a result, 
the total number of independent studies extracted may be larger than the number of articles selected, because one single article may report more than one study or compare the effects of collaboration, computer use, and/ or more than one learning tool.

Finally, the ESs were checked for potential outliers by examining whether an $E S$ differed by $>3 S D$ s, because extreme $E S$ s may have too much influence on further analysis. Four outliers were identified in the present study: one reported an $E S$ of 3.18 for individual knowledge gain (i.e., Y. T. C. Yang, 2015), one reported an $E S$ of 5.71 for content quality of individual writing (i.e., Gielen \& De Wever, 2015), one reported an ES of 3.35 for individual attitudes toward science and collaborative concept mapping (i.e., Lin, Chang, Hou, \& Wu, 2016), and one reported an ES of 3.23 for group task performance (i.e., Liu, Tan, \& Chu, 2009). The extraordinary effects are explored as follows. The study by Y. T. C. Yang (2015) examined the effects of digital gaming (vs. general technology-enhanced learning) on the development of employment-related skills and knowledge through CL in a business course. The experimental and control groups (with 68 students) were taught by the same instructor and used the same textbook, schedule, and evaluations developed based on the national vocational education curriculum. The control groups searched and evaluated online information for group analyses and debate of business cases, while the experimental groups engaged in multiplayer digital gaming, which simulated employment-related problems or cases. The groups in both conditions also wrote group reports and gave group presentations. After a 27-week intervention, the game learning was found to be more effective in terms of improving individual domain-related knowledge and skills. Gaming can stimulate students' interest and intrinsic motivation, and adequately simulate the complexities of workplace realities, which fits well with the learning topic in this experiment. In Gielen and De Wever (2015), the students who received additional guidance on how to provide informative feedback and suggestive elaborations for future improvement, significantly increased individuals' peer feedback content quality (or writing skills). In Lin et al. (2016), experimental groups used Google Docs to build concept maps and Google Chat for discussion, while control groups employed paper-and-pencil-based concept mapping and FTF discussion. The observation of the knowledge co-construction process and modification functions provided by the real-time coediting mechanism and revision history of Google Docs contributed to enhancing students' attitudes toward collaborative concept mapping. In Liu et al. (2009), the extraordinary effect might be due to the fact that mobile-supported immersive learning gave students direct access to context-aware content, while paper-based did not, in an outdoor learning setting. These ESs were modified to 3.00 using the Windsorising procedure described by Lipsey and Wilson (2001) to avoid their excessive influence.

\section{Calculation of Mean ES}

In this meta-analysis, the random effects model was used, considering the variability of designs, contexts, educational levels, and so on. When the ESs for all selected studies were calculated, they were then compiled and analyzed using the 


\section{Chen et al.}

random effects model to calculate the mean $E S$ for each outcome in each category mentioned above in the coding framework. Optimal weights attached to studies were commonly constructed using the inverse of variance, that is, $w=1 / S E^{2}$, calculated by Formula 4 .

$$
w=1 /\left(\frac{n_{1}+n_{2}}{n_{1} n_{2}}+\frac{g^{2}}{2\left(n_{1}+n_{2}\right)}\right)
$$

The weight $w$ is generally used in the fixed effects model. In the random effects model, the variance includes the within-studies variance $S E^{2}$ plus the between-studies variance $\tau^{2}$ (tau-square), that is, $w^{\prime}=1 /\left(S E^{2}+\tau^{2}\right)$. The between-studies variance $\tau^{2}$ can be calculated following the procedures provided by Hedges and Vevea (1998). The weight $w$ ' is more balanced compared to $w$. The weighted mean $E S$ for each outcome variable is then calculated using Formula 5 , denoted by $\bar{g}$.

$$
\bar{g}=\frac{\sum w_{i}^{\prime} g_{i}}{\sum w_{i}^{\prime}}
$$

where $g_{i}$ is Hedges's unbiased estimate of the $E S$ of each selected study and $w_{i}$ is the corresponding weight. The significance of $\bar{g}$ is checked by its $95 \%$ confidence interval. If the confidence interval does not include zero (i.e., the lower limit of the confidence interval is greater than zero), $\bar{g}$ is considered significantly positive, indicating that the results favor the treatment. If $\bar{g}$ is significantly negative, it indicates that the results favor the control condition. $\bar{g}$ can also be achieved by running the SPSS macros written by Wilson (latest version updated on August $11,2010)$.

\section{Homogeneity Analysis}

Homogeneity analysis is performed to investigate the variance in ESs across studies and to test whether the observed variance in the results is more heterogeneous than what might be expected from sampling variance alone (Cooper et al., 2009). When aggregating findings into categories, extreme variations may exist across interventions and contexts (Clark et al., 2016). In this study, the collection of $E S \mathrm{~s}$ for each outcome in each category was tested for homogeneity through the homogeneity statistic $\left(Q_{\mathrm{T}}\right) . Q_{\mathrm{T}}$ has an approximate chi-square $\left(\chi^{2}\right)$ distribution with $k-1$ degree of freedom, where $k$ is the number of studies. If $Q_{\mathrm{T}}$ value is smaller than the critical value, we will fail to reject the null hypothesis of homogeneity. In such cases, no tests of moderators are needed because it can be reasonably assumed that the data in the sample adequately represent the population under investigation (Springer et al., 1999). Otherwise, the set of ESs is significantly heterogeneous (i.e., significant differences exist), and thus, the random effects model will be used. In this meta-analysis, the homogeneity test for each category showed significant differences, verifying our selection of the random effects model in the mean $E S$ estimates. 


\section{Moderator Analysis}

The heterogeneity of studies also indicates that further grouping of individual $E S$ s is needed in search of potential moderators accounting for the variance among studies. In the current meta-analysis, substantive study features such as research design, treatment duration, and sample size were mainly tested as moderators through between-group homogeneity $\left(Q_{\mathrm{B}}\right)$ and within-group homogeneity $\left(Q_{\mathrm{W}}\right)$. $Q_{\mathrm{B}}$ examines the homogeneity of $E S$ s across groups and has an approximate $\chi^{2}$ distribution with $m-1$ degree of freedom, where $m$ is the number of groups. A statistically significant $Q_{\mathrm{B}}$ indicates that the potential moderator has a significant impact on the variance across subsets of studies. $Q_{\mathrm{W}}$, similar to $Q_{\mathrm{T}}$, examines the homogeneity of ESs within each group. It should be noted that Cooper et al. (2009) indicated that this statistic is only accurate when there are $>10$ studies in each group.

\section{Results}

A total of 425 studies reported in 356 articles met all of the inclusion criteria (only four were from the Google Scholar search results). Among these 425 studies, 84 were coded into Category 1 examining the effects of CL versus non-CL (or individual learning) on student academic achievement; 71 were coded into Category 2 investigating the effects of computer use for CL on student academic achievement or group task performance; 193 were coded into Category 3 studying the effects of using extra learning environments or tools, or supporting strategies, with 142 analyzed in the coding subcategories; and 77 were coded into Category 4 comparing two or more different tools or strategies.

\section{General Characteristics of the Selected Articles}

The articles selected were published between 2000 and 2016. There were fewer than five articles for each year between 2000 and 2004; however, the number of articles on CSCL has grown steadily each year, especially since 2005 . As mentioned by Jeong et al. (2014), 2005 was the year that CSCL became an established education approach. There were around 15 articles per year between 2005 and 2008 , and $>25$ per year from 2009 to 2016 .

With regard to the publication journals, the 356 selected articles were from 95 academic journals and one conference, and many were published in Computers \& Education (20.5\%, 73 articles), Computers in Human Behavior (10.7\%, 38 articles), Educational Technology \& Society (7.3\%, 26 articles), the International Journal of Computer-Supported Collaborative Learning (5.6\%, 20 articles), the Journal of Computer Assisted Learning (3.9\%, 14 articles), Interactive Learning Environments (3.6\%, 13 articles), Educational Technology Research and Development (2.8\%, 10 articles), the International Journal of Engineering Education (2.2\%, 8 articles), Instructional Science (2.0\%, 7 articles), and the Journal of Educational Computing Research (2.0\%, 7 articles). The possibility of publication bias within our samples was explored using funnel plots with pseudo 95\% confidence limits, as shown in Figures S1 and S2 in the Supplemental Material titled "Funnel Plots" (available in the online version of the journal). As presented in Supplemental Figures S1 and S2, studies with smaller sample sizes (with larger standard errors) are distributed around the mean effect size's both 
sides, and there are no obvious asymmetries, thus suggesting minimal publication bias.

\section{Effects of CL (Research Question 1)}

Research Question 1 examines the main effects of CL on individual knowledge, skills, and perceptions. Table 3 presents the total number of participants involved, the total number of studies included in Category 1, the number of independent studies for each outcome of interest (e.g., knowledge achievement), the weighted mean effect size $\bar{g}, 95 \%$ confidence interval, and homogeneity statistics $Q_{\mathrm{T}}$ for each outcome. It suggests that all mean $E S$ s were statistically significant, as indicated by the $95 \%$ confidence intervals, on the basis of the synthesis of 84 studies involving 11,684 participants. The number of independent studies is indicated by $k$ in the remainder of this article.

\section{Knowledge Achievement}

The weighted mean effect size $\bar{g}$ for individual knowledge achievement was $0.42(95 \%$ CI $[0.32,0.53], k=73)$, indicating a significant beneficial effect of CL on learners' knowledge gain. In other words, learners using CSCL had significantly better knowledge achievement than those who used computer-based individual learning. Individual effect sizes ranged from -1.28 to 2.59 .

Kolloffel, Eysink, and de Jong (2011), for example, examined the effects of collaboration in inquiry-based learning of combinatorics and probability theory in mathematics education. The experiment was conducted with 215 students (average age $=14.6$ years) for 6 weeks in a real school setting. The participants worked with authentic problems in a simulation-based learning environment. In the collaborative setting, students collaboratively planned and performed inquiry processes and explained their ideas to their partners. The reliability and validity of the pre- and posttests have been established in a number of previous studies. There was no significant difference in the pretest scores of the two conditions. Collaborative learners outperformed individual learners on intuitive knowledge and situational knowledge, with an $E S$ of 0.58 . Collaboration helps stimulate interpretation and sense-making processes that foster knowledge acquisition.

\section{Skill Acquisition}

$\bar{g}$ for individual skill acquisition was 0.64 (95\% CI [0.34, 0.94], $k=17)$, indicating a medium effect. Individual effect sizes ranged from -0.30 to 2.56 . In CL, students can better develop skills for argumentation, critical thinking, reasoning, elaboration, and so forth. For instance, Tsaushu et al. (2012) implemented group learning in a major research university in Israel with about 300 students who studied biology for 1 month. Students searched relevant information on a given topic, discussed and elaborated their understandings with peers, and designed their group presentations. They outperformed those learning individually in terms of higher order thinking skills $(E S=0.45)$.

\section{Perceptions \\ $\bar{g}$ for perceptions was $0.38(95 \% \mathrm{CI}[0.22,0.55], k=26)$, indicating a small effect of CL on learners' perceptions. Individual effect sizes ranged from -0.25 to}




\section{TABLE 3}

Overall weighted mean effect sizes for Category 1 (effects of CL), Category 2 (effects of computer use), and Category 3 (effects of learning environments or tools, and supporting strategies)

\begin{tabular}{llllllll}
\hline Participants & $N$ & Outcome & $k$ & $\bar{g}$ & $95 \% \mathrm{CI}$ & $Q_{\mathrm{T}}$ \\
\hline
\end{tabular}

Category 1 (CL vs. non-CL in computer-supported settings)

$\begin{array}{cclllll}11,684\left(N_{\text {Exp }}=6,378, \quad 84\right. & \text { Knowledge } & 73 & 0.42 & {[0.32,0.53]} & 93.59^{*} \\ \left.N_{\text {Ctrl }}=5,306\right) & & \text { Skill } & 17 & 0.64 & {[0.34,0.94]} & 18.18 \\ & & \text { Perceptions } & 26 & 0.38 & {[0.22,0.55]} & 28.90\end{array}$

Category 2 (computer use vs. no computer use in CL settings)

\begin{tabular}{|c|c|c|c|c|c|}
\hline \multirow{5}{*}{$\begin{array}{c}11,286\left(N_{\text {Exp }}=5,471,\right. \\
\left.N_{\text {Ctrl }}=5,815\right)\end{array}$} & Knowledge & 64 & 0.45 & {$[0.33,0.56]$} & $90.51 *$ \\
\hline & Skill & 9 & 0.53 & {$[0.34,0.72]$} & 8.60 \\
\hline & $\begin{array}{l}\text { Group task } \\
\text { performance }\end{array}$ & 14 & 0.89 & {$[0.43,1.36]$} & 15.73 \\
\hline & Social interaction & 5 & 0.57 & {$[0.28,0.86]$} & 3.29 \\
\hline & Perceptions & 23 & 0.51 & {$[0.21,0.81]$} & $39.39 *$ \\
\hline
\end{tabular}

Category 3 (with vs. without learning environment or tool in CSCL)

\begin{tabular}{|c|c|c|c|c|c|c|}
\hline \multirow{5}{*}{$\begin{array}{c}7,190\left(N_{\text {Exp }}=3,706,\right. \\
\left.N_{\text {Ctrl }}=3,484\right)\end{array}$} & \multirow[t]{5}{*}{77} & Knowledge & 61 & 0.55 & {$[0.39,0.71]$} & $84.35^{*}$ \\
\hline & & Skill & 10 & 0.79 & {$[0.42,1.15]$} & 11.72 \\
\hline & & $\begin{array}{l}\text { Group task } \\
\text { performance }\end{array}$ & 31 & 0.66 & {$[0.42,0.90]$} & 40.22 \\
\hline & & Social interaction & 27 & 0.40 & {$[0.25,0.55]$} & 25.51 \\
\hline & & Perceptions & 32 & 0.32 & {$[0.18,0.46]$} & 30.07 \\
\hline
\end{tabular}

Category 3 (with vs. without supporting strategy in CSCL)

\begin{tabular}{|c|c|c|c|c|c|c|}
\hline \multirow{5}{*}{$\begin{array}{c}6,269\left(N_{\text {Exp }}=3,369\right. \\
\left.N_{\text {Ctrl }}=2,900\right)\end{array}$} & \multirow[t]{5}{*}{65} & Knowledge & 42 & 0.38 & {$[0.26,0.51]$} & 56.51 \\
\hline & & Skill & 15 & 0.65 & {$[0.28,1.03]$} & 18.33 \\
\hline & & $\begin{array}{l}\text { Group task } \\
\text { performance }\end{array}$ & 21 & 0.45 & {$[0.21,0.69]$} & 22.17 \\
\hline & & Social interaction & 28 & 0.58 & {$[0.41,0.74]$} & 35.47 \\
\hline & & Perceptions & 26 & 0.23 & {$[0.07,0.38]$} & 33.12 \\
\hline
\end{tabular}

Note. $N_{\text {Exp }}=$ participants in the experimental group; $N_{\text {Crrl }}=$ participants in the control group; $N=$ total number of independent studies included; $k=$ number of independent studies analyzed for each learning outcome or process; $\bar{g}=$ weighted mean effect size; $\mathrm{CI}=$ confidence interval; $Q_{\mathrm{T}}=$ total homogeneity statistics. ${ }^{*} p<.05$.

1.73. CL can foster students' positive perceptions. An example study by Sung and Hwang (2013) suggested that collaborative game-based learning (by role-playing in groups of 3 or 4 members) improved students' motivation, attitudes toward science, as well as academic achievement, compared with individual game learning, in an elementary natural science course.

All mean $E S$ s were large enough to be considered substantively important for instruction (i.e., $>0.20$ ), indicating that $\mathrm{CL}$ was more effective than individual learning in computer-supported settings. 


\section{Moderator Analysis}

As can be seen in Table 3, homogeneity statistics for knowledge achievement suggest significant variances in ESs across studies. Therefore, further grouping of $E S$ s is needed in the search for potential moderators. In this meta-analysis, educational level, subject area, test type, research design, sample size, and duration were analyzed. The results of homogeneity analysis show that there was no significant variability between the different educational levels $\left(Q_{\mathrm{B}}=1.04, d f=3, p\right.$ $>.05)$ or between different subject areas $\left(Q_{\mathrm{B}}=2.84, d f=5, p>.05\right)$. In addition, homogeneity analysis of test type revealed significant difference in the magnitude of ESs for local tests $(\bar{g}=0.45,95 \%$ CI $[0.34,0.57], k=66)$ and standardized tests $(\bar{g}=0.29,95 \%$ CI $[0.07,0.50], k=6)$. Yet due to the disparity in the numbers of sample studies and relatively few studies with standardized tests, this result should be interpreted with caution. However, both types of tests showed significantly positive effects of CL.

\section{Research design}

$E S$ s for knowledge measure may also vary according to the nature of the study research design. The results in Table 5 show significant variance between randomized experimental $(\bar{g}=0.27)$ and quasi-experimental $(\bar{g}=0.54)$ studies.

\section{Sample size}

Sample size may contribute to the variation in ESs for knowledge measure. As shown in Table 5, there is significant variance between different sample sizes. The mean $E S$ for studies with sample size $<100$ was 0.45 , whereas the mean $E S$ for studies with sample size ranging from 100 to 250 was 0.51 , and it was 0.25 for studies with sample size $>250$. Small sample studies tend to produce larger ESs. However, Hedges's $g$ and the random effects model did correct the effect of small samples (i.e., studies with larger sample sizes would have greater weight on the mean $E S$ and studies with small sample sizes would have less weight on the overall mean ES (Lipsey \& Wilson, 2001). Despite the variance between different sample sizes, the mean $E S$ s were all significantly positive.

\section{Duration}

Intervention duration also significantly contributed to the variance between studies. Studies conducted between 1 month and 1 semester (i.e., $<1$ semester) reported the largest effect size $(\bar{g}=0.52)$. This indicates that it is not necessarily the case that the longer the collaboration duration, the better the effects.

Moreover, it seems that the learning efficiency of collaboration was higher for high-complexity tasks than for low-complexity tasks (e.g., simple recall of learning content). For example, in Rebetez et al. (2010), after an introduction to the phenomenon of the Venus transit, students were asked to explain the phenomenon, with individual learners reflecting by themselves and collaborative learners discussing in dyads. This study found a negative $E S$ for knowledge retention and transfer. Task complexity seems to be an influencing factor. However, it is hard to determine the task complexity from the information reported in the studies. 


\section{Effects of Computer Use (Research Question 2)}

Research Question 2 examines the effects of computer use on individual knowledge gain, skill acquisition, group task performance, perceptions, and social interaction. Table 3 presents the total number of participants involved, the total number of independent studies included, the number of independent studies for each outcome variable, the weighted mean $E S, 95 \%$ confidence interval, and the homogeneity statistics for each outcome. It suggests that all weighted mean ESs are statistically significant as indicated by the $95 \%$ confidence intervals, by combining 71 studies involving 11,286 participants.

\section{Knowledge Achievement}

The weighted mean effect size $\bar{g}$ for individual knowledge achievement was $0.45(95 \%$ CI [ $0.33,0.56], k=64)$, indicating a near medium effect of computer use on learners' knowledge gain. Individual effect sizes ranged from -0.86 to 1.96. For instance, Genlott and Grönlund (2016) tested the effects of ICT on CL of literacy and mathematics among 375 participants for 3 years. Students in the ICT condition iteratively used computers or tablets and software tools (e.g., Google Drive or Google Sites) to collaboratively write texts or do reasoning, subsequently discuss and refine their work together, and give each other formative feedback and assessment through shared digital documents, called the "Write to Learn" (WTL) method. Students in the control condition communicated orally without access to ICT. The WTL method has been used more or less in all subjects in a Swedish city. This study reported an ES of 0.40 for literacy achievement and 0.35 for mathematics achievement in the Swedish national tests.

\section{Skill Acquisition}

$\bar{g}$ for individual skill acquisition was 0.53 (95\% CI [0.34, 0.72], $k=9)$, indicating a medium effect of computer use on learners' skill acquisition. Individual effect sizes ranged from -0.08 to 0.97 . For example, K. Y. Yang and Heh (2007) compared the impacts of the Internet Virtual Physics Laboratory with a traditional laboratory on collaborative problem solving among four classes of 150 Taiwanese 10th graders. The experiment lasted for 6 weeks. The participants in the virtual laboratory condition used virtual tools to observe physics phenomena, measure variables, and record and analyze data. They achieved significantly better science process and problem-solving skills measured by a test with high reliability and validity than those using the traditional laboratory.

\section{Group Task}

$\bar{g}$ for group task performance was 0.89 (95\% CI $[0.43,1.36], k=14)$, a large effect size, meaning that computer use significantly improved the group's task performance. Individual effect sizes ranged from -0.75 to 3.23. Roseth et al. (2011), for example, in a randomized experiment compared the effects of CMC with FTF communication on learning in a seven-session collaborative controversy task among teacher education undergraduates in a public American university. Learners in the CMC condition used Skype, video, audio, or Google Docs to communicate. Paired learners conducted deliberate discourse, reached agreement, and completed 
Chen et al.

an integrative essay. Results showed that students in the CMC condition submitted significantly higher quality essays than those in the FTF condition.

\section{Social Interaction}

$\bar{g}$ for social interaction was $0.57(95 \%$ CI $[0.28,0.86], k=5)$, indicating that computer use greatly promoted the interactions between group members. Individual effect sizes ranged from 0.27 to 0.99. Smith, Wilson, Banks, Zhu, and Varma-Nelson (2014) examined the transfer of peer-led CL from FTF to an online environment using Web conferencing technology in a university chemistry course with about 400 students for one semester. It concluded that synchronous computer-mediated student interactions enabled comparable peer collaboration with those of FTF communication $(E S=0.27)$.

\section{Perceptions}

$\bar{g}$ for perceptions was $0.51(95 \%$ CI $[0.21,0.81], k=23)$, indicating that learners had quite positive perceptions. Individual effect sizes ranged from -1.22 to 3.35. An example study by Chen and Chen (2014) found that after 2 weeks of CL by sharing annotations or comments on reading materials, students using a digital reading system to make annotations significantly improved their reading attitudes compared with their counterparts who used hand-written paper-based annotations $(E S=0.25)$.

All mean $E S$ s were large enough to be considered substantively important for instruction practices, indicating that, in CL, students with computer use achieved more than those who did not use computers.

\section{Moderator Analysis}

The $Q_{\mathrm{T}}$ statistics (reported in Table 3 ) reveal significant variances in individual $E S$ s for knowledge achievement and perceptions, suggesting that further grouping of the ESs is needed in the search for potential moderators. The results of homogeneity analysis show that there was no significant variability between the different educational levels $\left(Q_{\mathrm{B}}=4.07, d f=4, p>.05\right)$ or between different subject areas $\left(Q_{\mathrm{B}}=6.92, d f=7, p>.05\right)$. In addition, homogeneity analysis of test type did not reveal significant variance $\left(Q_{\mathrm{B}}=2.98, d f=1\right)$ in the $E S \mathrm{~s}$ for local tests $(\bar{g}$ $=0.42,95 \%$ CI $[0.29,0.54], k=52)$ or standardized tests $(\bar{g}=0.40,95 \% \mathrm{CI}$ $[0.13,0.67], k=11)$. They both led to significantly positive effects.

\section{Research design, sample size, and duration}

Similar to the results of the moderator analyses for Category 1 , there were significant variances across different research designs, sample sizes, and durations, as shown in Table 5. Quasi-experimental and small sample studies tended to produce larger ESs. Moreover, when the intervention duration is from 1 month to 1 semester, the effects of computer use seem to be stronger.

\section{Effects of Using Extra Learning Environments or Tools, or Supporting Strategies (Research Question 3)}

\section{Learning Environments or Tools}

A total of 77 studies examining the effects of using extra learning environments or tools and involving 7,190 participants were analyzed. The effects of 
different environments or tools were positive for all outcome and process measures, as can be seen in Table 3. The effects of separate tools are presented in Table 4.

\section{Knowledge achievement}

As shown in Table 3, the weighted mean effect size $\bar{g}$ was 0.55 (95\% CI [0.39, $0.71], k=61$ ) for individual knowledge achievement, indicating the effectiveness of tools on learners' knowledge gain. The $Q_{\mathrm{T}}$ statistics revealed significant variance in the individual effect sizes of the 61 studies reporting knowledge achievement $\left(Q_{\mathrm{T}}=84.35, d f=60, p<.05\right)$. As shown in Table 4 , effect sizes for the seven analyzed learning environments or tools ranged from 0.15 to 0.67 , all being significantly positive except for the Basic Online Discussion Tools $(\bar{g}=0.52$, $95 \%$ CI $[-0.66,1.70], k=8)$ and Enhanced Online Discussion Tools $(\stackrel{g}{g}=0.15$, $95 \%$ CI $[-0.17,0.47], k=7)$. Larger effect sizes were found for the Group Awareness Tools $(\bar{g}=0.63,95 \%$ CI [0.48, 0.77], $k=10)$ and Graphs or Multimedia $(\bar{g}=0.67,95 \%$ CI $[0.23,1.11], k=4)$. There was significant variance between the seven learning environments or tools $\left(Q_{\mathrm{B}}=17.63, d f=6, p<\right.$ $.05)$. An example study on Graphs or Multimedia by Rebetez et al. (2010) investigated the effects of animation (compared with static graphics) on learning natural or dynamic systems via peer discussion in a university geology course. After watching the phenomena (e.g., a moon eclipse) presented by animations or static graphics, dyads reflected on and shared their understandings. This study indicated that animations improved students' knowledge retention and transfer scores (ES $=0.70$ ), as animations could present the dynamic nature of the phenomenon and promote students' construction of a dynamic mental model.

\section{Skill acquisition}

The weighted mean effect size $\bar{g}$ was $0.79(95 \%$ CI $[0.42,1.15], k=10)$ for skill acquisition, reaching a large level (see Table 3 ). The $Q_{\mathrm{T}}$ statistics revealed no significant variance in the individual effect sizes of the 10 studies reporting skill results $\left(Q_{\mathrm{T}}=11.72, d f=9, p>.05\right)$. All effect sizes for the seven learning environments or tools were positive, ranging from 0.42 to 1.20 (see Table 4). For example, as mentioned above, in Y. T. C. Yang (2015), experimental groups used digital game-based learning, while control groups used general technologyenhanced learning (e.g., online search for information) for CL of employmentrelated knowledge and skills in a business course. Digital game-based learning significantly fostered student higher order thinking skills after a 27-week intervention $(E S=1.35)$.

\section{Perceptions}

The weighted mean effect size $\bar{g}$ was $0.32(95 \%$ CI $[0.18,0.46], k=32)$ for learners' perceptions, a small-level effect size. The $Q_{\mathrm{T}}$ statistics revealed no significant variance in the individual effect sizes of the 32 studies reporting students' perceptions $\left(Q_{\mathrm{T}}=30.07, d f=31, p>.05\right)$. As shown in Table 4, almost all mean effect sizes were significantly positive, except for Basic Online Discussion $(\bar{g}=0.23,95 \%$ CI $[-0.37,0.83], k=3)$, the Visual Representation Tools 


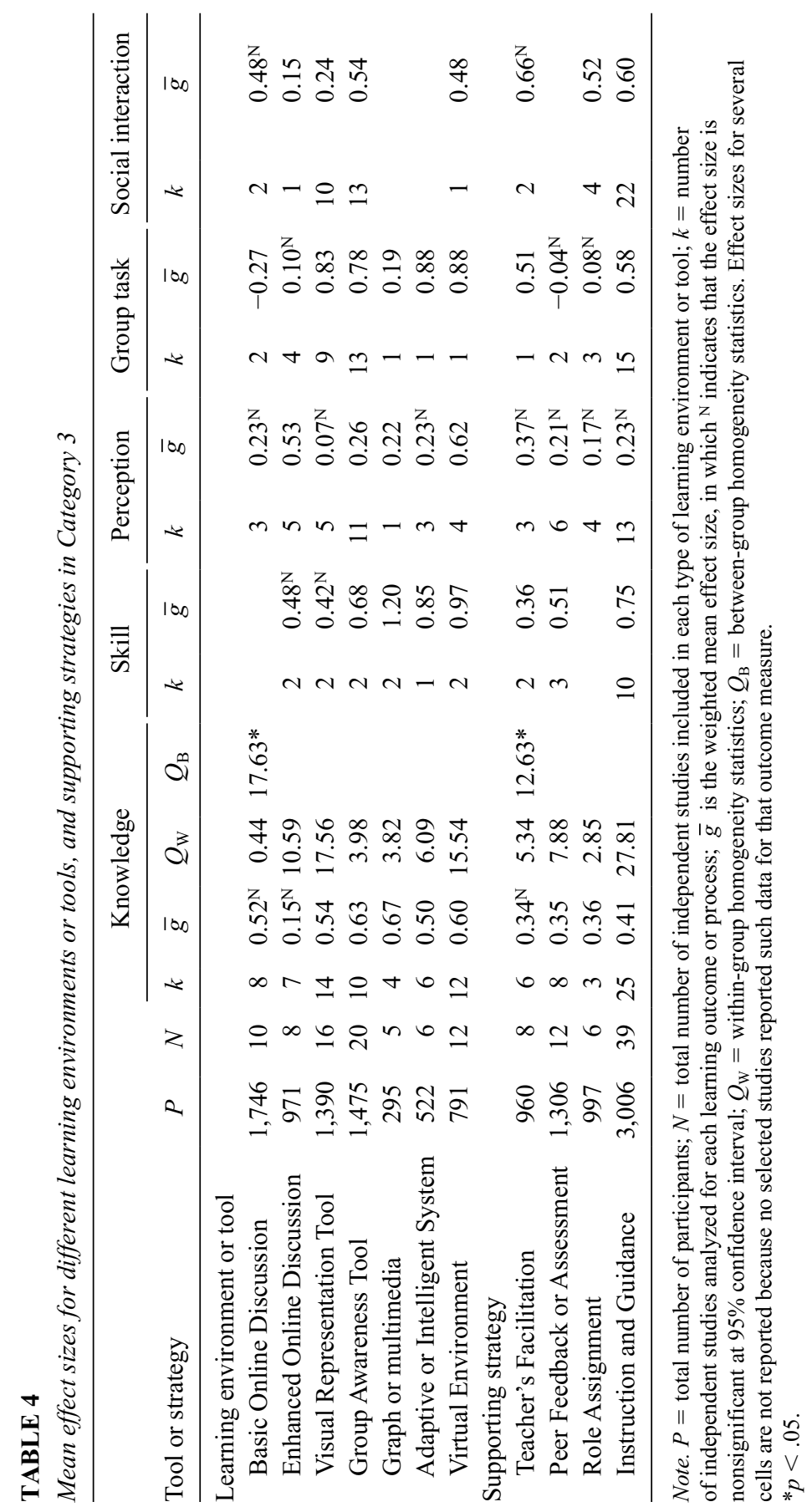


$(\bar{g}=0.07,95 \%$ CI $[-0.44,0.59], k=5)$, and the Adaptive or Intelligent Systems $(\bar{g}=0.23,95 \%$ CI $[-0.30,0.77], k=3)$. They reached a medium level for Enhanced Online Discussion $(\bar{g}=0.53,95 \%$ CI $[0.13,0.93], k=5)$ and Virtual Environments ( $\bar{g}=0.62,95 \%$ CI $[0.32,0.91], k=4)$. For example, Saltarelli and Roseth (2014) compared the effects of synchronous CMC (via instant text-based chat and real-time coediting of written assignment) with asynchronous CMC (via general text-based chat) in an online educational psychology course. They found that synchronous CMC (i.e., Enhanced Online Discussion) promoted social interdependence, a sense of belonging, and intrinsic motivation, with an ES of 0.52.

\section{Group task}

The weighted mean effect size $\bar{g}$ was 0.66 (95\% CI [0.42, 0.90], $k=31)$ for group task performance, indicating that these tools were quite effective in terms of improving group performance. The $Q_{\mathrm{T}}$ statistics revealed no significant variance in individual effect sizes $\left(Q_{\mathrm{T}}=40.22, d f=30, p>.05\right)$. As seen in Table 4, among the seven tools, Visual Representation Tools and the Group Awareness Tools had large effect sizes, $0.83(95 \%$ CI $[0.35,1.31], k=9)$ and $0.78(95 \% \mathrm{CI}$ $[0.42,1.14], k=13)$, respectively; Enhanced Online Discussion did not reach a significant effect size $(\bar{g}=0.10,95 \%$ CI $[-0.36,0.56], k=4)$. An empirical study on Visual Representation Tool by Janssen et al. (2010) investigated the role of a graphical debate tool in facilitating student argumentation. Students were asked to analyze, reason, argue in groups, and write a group essay based on given materials. Experimental groups wrote essays of higher quality in terms of grounds than control groups using a textual debate tool, as the Visual Representation Tool could externalize complex ideas in a flexible way to support argumentation.

\section{Social interaction}

The weighted mean effect size $\bar{g}$ was $0.40(95 \%$ CI $[0.25,0.55], k=27)$ for social interaction, indicating that these tools were quite effective in terms of promoting students' discussion. The $Q_{\mathrm{T}}$ statistics revealed no significant variance in individual effect sizes $\left(Q_{\mathrm{T}}=25.51, d f=26, p>.05\right)$. As seen in Table 4 , among the several tools, the Group Awareness Tools $(\bar{g}=0.54,95 \%$ CI $[0.32,0.77]$, $k=13)$ and the Visual Representation Tools ( $\bar{g}=0.24,95 \%$ CI $[0.02,0.45], k=10)$ greatly promoted student social interaction. An example study by Buder and Bodemer (2008) tested a participation awareness tool with 64 university students (not majoring in physics), who discussed a physics controversy about "How far does light go." The small groups in the control condition were only provided with an online discussion environment. Those in the experimental condition were additionally provided with a Group Awareness Tool to rate peer contributions and were found to produce more knowledge construction contributions.

\section{Supporting Strategy}

A total of 65 studies examining the effects of using extra supporting strategies in CSCL and involving 6,269 participants were analyzed. Similar to technology tools, the overall effects of the analyzed supporting strategies were positive for all 
Chen et al.

outcomes, as shown in Table 3. The effects of separate strategies are presented in Table 4.

\section{Knowledge achievement}

As shown in Table 3, the weighted mean effect size for the four analyzed strategies was $0.38(95 \%$ CI $[0.26,0.51], k=42)$ for individual knowledge achievement, indicating the effectiveness of strategies on learners' knowledge gain. The $Q_{\mathrm{T}}$ statistics $\left(Q_{\mathrm{T}}=56.51, d f=41, p>.05\right)$ revealed no significant variance in individual effect sizes. As seen in Table 4, effect sizes for the four analyzed strategies ranged from 0.34 to 0.41 , all being significantly positive, except for Teachers' Facilitation $(\bar{g}=0.34,95 \%$ CI $[-0.01,0.68], k=6)$. There was significant variance between the four strategies $\left(Q_{\mathrm{B}}=12.63, d f=3, p<.05\right)$. Among the four strategies, the largest mean effect size was found for CSCL with Instruction and Guidance $(\bar{g}=0.41,95 \%$ CI $[0.19,0.63], k=25)$. For instance, Peterson and Roseth (2015) reported a randomized empirical study to examine the effects of collaboration script for online CL among 285 nursing students. This study presented an ES of 0.42 for individual students' knowledge achievement.

\section{Skill acquisition}

The weighted mean effect size was $0.65(95 \%$ CI $[0.28,1.03], k=15)$ for skill acquisition, reaching a medium level. $Q_{\mathrm{T}}$ statistics revealed no significant variance in individual effect sizes of the 15 studies reporting skill results $\left(Q_{\mathrm{T}}=18.33\right.$, $d f=14, p>.05)$. All effect sizes were significantly positive, ranging from 0.36 to 0.75 , with the largest being found for Instruction and Guidance $(\bar{g}=0.75$, 95\% CI $[0.32,1.19], k=10)$. Xiao and Lucking (2008), for example, examined the effects of Peer Feedback in improving writing skills by collaborative writing within a Wiki environment and indicated that students performing Peer Feedback significantly improved their writing skills $(E S=0.54)$.

\section{Perceptions}

The weighted mean effect size was $0.23(95 \%$ CI $[0.07,0.38], k=26)$. The $Q_{\mathrm{T}}$ statistics revealed no significant variance in the individual effect sizes $\left(Q_{\mathrm{T}}=\right.$ $33.12, d f=25, p>.05)$. However, all of the four supporting strategies failed to reach a significant level, although all were positive (see Table 4). For example, Xiao and Lucking's (2008) study mentioned above also reported positive effects of Peer Feedback on improving students' satisfaction with learning $(E S=0.47)$.

\section{Group task}

The weighted mean effect size for the four strategies was 0.45 (95\% CI [0.21, $0.69], k=21)$. The $Q_{\mathrm{T}}$ statistics revealed no significant variance in individual effect sizes $\left(Q_{\mathrm{T}}=22.17, d f=20, p>.05\right)$. The Peer Assessment or Peer Feedback, and Role Assignment did not seem to exert a positive impact on group task performance $(\bar{g}=-0.04$ and 0.08$)$. Surprisingly, Instruction and Guidance produced a significant medium effect size ( $\bar{g}=0.58,95 \%$ CI $[0.30,0.86], k=15)$ on group task performance. For example, Noroozi, Teasley, Biemans, Weinberger, and Mulder (2013) randomly assigned 120 undergraduate students to script and 
nonscript conditions to collaboratively analyze, discuss, and solve an authentic complex problem in an asynchronous text-based discussion board, with scripted groups arriving at higher quality solutions than nonscripted groups $(E S=0.77)$.

\section{Social interaction}

The weighted mean effect size was $0.58(95 \%$ CI $[0.41,0.74], k=28)$, revealing that learners using these strategies engaged more in the group discourse and interaction. The $Q_{\mathrm{T}}$ statistics revealed no significant variance across the four strategies $\left(Q_{\mathrm{T}}=35.47, d f=27, p>.05\right)$. Instruction and Guidance and Role Assignment produced significantly medium effect sizes, 0.60 (95\% CI [0.38, $0.82], k=22)$ and $0.52(95 \% \mathrm{CI}[0.23,0.81], k=4)$ respectively, indicating that the two strategies were especially effective in terms of promoting collaborative interactions. The example study mentioned above also reported that collaboration scripts promoted the transactive knowledge sharing and co-construction process with an $E S$ of 0.62 .

\section{Moderator Analysis}

The homogeneity analysis of test type did not reveal a significant difference in the magnitude of effect sizes for local tests $(\bar{g}=0.46,95 \% \mathrm{CI}[0.36,0.56], k=$ 99) or for standardized tests (only two studies). Regarding the moderating effects of research design, sample size, and intervention duration, there were significant variances across different research designs, sample sizes, and durations, as shown in Table 5. Quasi-experimental and randomized experimental studies produced equal effect sizes. Small-sample studies tended to produce larger effects. When the intervention duration was from 1 month to 1 semester, the effects seemed to be the smallest.

\section{Discussion}

Overall, CL, computer use, and the use of extra technology-enhanced environments or tools, or supporting strategies were found to produce positive effects on students' learning outcomes and learning processes in CSCL contexts.

\section{Effects of $C L$}

Learners with CSCL achieved significantly greater knowledge gains $(E S=0.42)$ exhibited better skills $(E S=0.64)$ and had more positive perceptions $(E S=0.38)$ than their counterparts in computer-supported individual learning, suggesting that CL was efficient enough to be considered of substantive importance. The effects on academic achievement - including knowledge and skills gain - and perceptions were much stronger than those reported by Lou et al. (2001), who revealed an $E S$ of 0.15 for achievement and nonsignificant positive attitudes toward computers $(E S=0.02)$, subject or instruction $(E S=0.07)$, and academic self-concept $(E S=0.04)$. Moreover, CL as a pedagogical approach to learning seems to have similar impacts on individual achievement in both computer-supported and traditional FTF settings (i.e., without computer support), as the meta-analysis by Kyndt et al. (2013) reported an ES of 0.54 for CL in traditional settings. However, in computer settings, learners have more positive perceptions of collaboration, clearly differing from the $E S$ of 0.18 reported by Kyndt et al. (2013). 


\section{TABLE 5}

Differences in mean effect sizes of knowledge achievement for other study features: research design, sample size, and duration

\begin{tabular}{|c|c|c|c|c|c|}
\hline Moderator variable & $N$ & $\bar{g}$ & $95 \% \mathrm{CI}$ & $Q_{\mathrm{W}}$ & $Q_{\mathrm{B}}$ \\
\hline \multicolumn{6}{|l|}{ Category 1} \\
\hline \multicolumn{6}{|l|}{ Research design } \\
\hline 1. Experimental & 25 & 0.27 & {$[0.10,0.44]$} & 22.65 & \multirow[t]{3}{*}{$5.44^{*}$} \\
\hline 2. Quasi-experimental & 36 & 0.54 & {$[0.38,0.70]$} & $52.07^{*}$ & \\
\hline 3. Not mentioned & 12 & 0.39 & {$[0.22,0.56]$} & 13.43 & \\
\hline \multicolumn{6}{|l|}{ Sample size } \\
\hline 1. $<100$ & 41 & 0.45 & {$[0.29,0.61]$} & 50.19 & \multirow[t]{3}{*}{$8.22 *$} \\
\hline 2. $100-250$ & 19 & 0.51 & {$[0.30,0.72]$} & 22.31 & \\
\hline $3 . \geqslant 250$ & 13 & 0.25 & {$[0.06,0.44]$} & 12.87 & \\
\hline \multicolumn{6}{|l|}{ Duration } \\
\hline 1. $<1$ month & 28 & 0.36 & {$[0.17,0.54]$} & 37.13 & \multirow[t]{3}{*}{$11.11^{*}$} \\
\hline 2. 1 month to 1 semester & 22 & 0.52 & {$[0.27,0.77]$} & 24.94 & \\
\hline $3 . \geqslant 1$ semester & 24 & 0.40 & {$[0.25,0.54]$} & 19.41 & \\
\hline \multicolumn{6}{|l|}{ Category 2} \\
\hline \multicolumn{6}{|l|}{ Research design } \\
\hline 1. Experimental & 16 & 0.09 & {$[-0.17,0.35]$} & 15.75 & \multirow[t]{3}{*}{$10.36^{*}$} \\
\hline 2. Quasi-experimental & 35 & 0.63 & {$[0.48,0.79]$} & $49.16^{*}$ & \\
\hline 3. Not mentioned & 13 & 0.40 & {$[0.21,0.58]$} & 15.24 & \\
\hline \multicolumn{6}{|l|}{ Sample size } \\
\hline 1. $<100$ & 41 & 0.57 & {$[0.40,0.75]$} & 41.15 & \multirow[t]{3}{*}{$21.93 *$} \\
\hline 2. $100-250$ & 16 & 0.29 & {$[0.01,0.57]$} & 18.57 & \\
\hline $3 . \geqslant 250$ & 7 & 0.28 & {$[0.11,0.46]$} & 8.86 & \\
\hline \multicolumn{6}{|l|}{ Duration } \\
\hline 1. $<1$ month & 18 & 0.45 & {$[0.11,0.80]$} & 14.66 & \multirow[t]{3}{*}{$15.41^{*}$} \\
\hline 2. 1 month to 1 semester & 29 & 0.45 & {$[0.25,0.65]$} & 31.99 & \\
\hline 3. $\geqslant 1$ semester & 16 & 0.43 & {$[0.28,0.58]$} & $28.45^{*}$ & \\
\hline \multicolumn{6}{|l|}{ Category 3} \\
\hline \multicolumn{6}{|l|}{ Research design } \\
\hline 1. Experimental & 53 & 0.46 & {$[0.33,0.59]$} & 60.64 & \multirow[t]{3}{*}{$6.93 *$} \\
\hline 2. Quasi-experimental & 44 & 0.46 & {$[0.30,0.61]$} & $73.76^{*}$ & \\
\hline 3. Not mentioned & 6 & 0.36 & {$[0.13,0.60]$} & 4.02 & \\
\hline \multicolumn{6}{|l|}{ Sample size } \\
\hline 1. $<100$ & 75 & 0.51 & {$[0.37,0.65]$} & 88.63 & \multirow[t]{3}{*}{$31.41^{*}$} \\
\hline 2. $100-250$ & 21 & 0.36 & {$[0.22,0.50]$} & 20.50 & \\
\hline $3 . \geqslant 250$ & 7 & 0.32 & {$[0.07,0.56]$} & 4.81 & \\
\hline \multicolumn{6}{|l|}{ Duration } \\
\hline 1. $<1$ month & 53 & 0.52 & {$[0.37,0.67]$} & 62.23 & \multirow[t]{3}{*}{$9.34^{*}$} \\
\hline 2. 1 month to 1 semester & 28 & 0.29 & {$[0.13,0.44]$} & 33.15 & \\
\hline 3. $\geqslant 1$ semester & 22 & 0.54 & {$[0.35,0.74]$} & $40.63^{*}$ & \\
\hline
\end{tabular}

$* p<.05$. 
There are several reasons for the differences in the magnitude of ES between Lou et al.'s (2001) study and this current meta-analysis. First, there are methodological differences, as this current study employs much stricter inclusion criteria. For example, the current study controlled the baseline equivalence between experimental and control conditions when selecting empirical studies (see Inclusion Criterion 3), as baseline differences are highly likely to be alternative explanations for research findings; Lou et al.'s meta-analysis did not use such inclusion criteria. In addition, this study only includes studies that must have reported academic achievement, while Lou et al. did not employ such a selection criterion. Another difference is that most of the studies included in this metaanalysis are published journal articles, compared with only about half of the studies included in Lou et al.'s analysis (with the other half being unpublished reports or doctoral dissertations).

Another reason for the exhibited differences in ES magnitude may be that students have had more frequent access to computers in recent years compared with those of 20 years ago. As such, they may have adapted to using computers in learning and will not experience difficulties operating computers when engaging in CSCL. The advocation of collaborative skills in the past decades may also have encouraged CL in formal classroom learning. Thus, students have more prior group learning experience, a factor that is extremely important, according to Fransen, Weinberger, and Kirschner (2013).

This effect may have been strengthened by the fact that information technologies have developed greatly and become more sophisticated, and correspondingly, their applications in education may have made a difference in enhancing CL. Yet the computer programs or software employed in the meta-analysis by Lou et al. (2001) included tutoring systems, computer-based inquiry learning environments, general purpose software such as word processing, spreadsheets, and CMC media such as email. These environments were predominantly simple CMC systems that are limited in their ability to convey feelings of sociability, social presence, and social space (P. A. Kirschner, Kreijns, \& Jochems, 2003; Kreijns et al., 2003; Kreijns, Kirschner, Jochems, \& Van Buuren, 2004). The studies analyzed in the present meta-analysis deployed many sophisticated learning environments, tools, or strategies, such as visual representations (e.g., Kwon \& Cifuentes, 2009) and educational game-based learning environments (e.g., Ke, 2008; Sung \& Hwang, 2013). These environments or strategies may better support learning in terms of conceptual understanding, problem-solving skills, engagement, and attitudes (Kolloffel et al., 2011; Sung \& Hwang, 2013).

\section{Effects of Computer Use}

When comparing CSCL with traditional FTF CL, we found significant positive effects of computer use on knowledge gain $(E S=0.45)$, skill acquisition $(E S=$ $0.53)$, students' perceptions $(E S=0.51)$, group task performance $(E S=0.89)$, and social interaction $(E S=0.57)$. These results are encouraging.

Computer use can make a difference to student learning outcomes and group discourse (Resta \& Laferrière, 2007). First, the use of computer technologies can create interactive and engaging learning environments with organized learning material (P. A. Kirschner, Kirschner, \& Janssen, 2014; Tsuei, 2011), enabling 


\section{Chen et al.}

students to adopt an active learning approach, increase their levels of interest, and develop high-level thinking (Frailich et al., 2009; Lan, Sung, \& Chang, 2009). Second, CMC allows flexible time for students to prepare for interaction and to reflect on, understand, and articulate what others have said (Chen \& Chen, 2014). Third, students may feel more comfortable and free in CSCL, especially the vulnerable and passive learners. They possibly avoid the embarrassment of revealing their shortcomings or different perspectives to their peers in FTF settings but become more willing to express their ideas via computers (Frailich et al., 2009; Tsuei, 2011). They increased their self-confidence, incentives, and interest in communicating by written language (Genlott \& Grönlund, 2016). In other words, they might experience increased psychological safety in online settings (Kreijns et al., 2004). All of these resulted in more durable and equal communication (Genlott \& Grönlund, 2016), and more engagement in more complex and cognitively challenging online discussions compared to those in FTF groups (BenbunanFich, Hiltz, \& Turoff, 2002), consequently enhancing the learning outcomes (Corter et al., 2011).

\section{Effects of Using Extra Learning Environments or Tools, or Supporting Strategies}

Medium ESs on knowledge achievement were found in almost all of the analyzed learning environments or tools except for the Enhanced Online Discussion tools. There was significant difference between these environments or tools. The Group Awareness Tools seemed to be the most promising in all aspects of learning outcomes and processes. Visualization of group members' participation and knowledge level had a significant influence on group activities and task performance (Janssen et al., 2007). For successful collaboration, it is important that individuals make contributions and are aware of the knowledge or expertise and social presence of group members (Kreijns et al., 2004). The social comparison theory (Festinger, 1954) may explain the effect of social group awareness in coordinating collaboration, whereas cognitive load theory may explain why cognitive group awareness reduces the efforts to regulate task activities and encourages elaborated explanations (P. A. Kirschner \& Erkens, 2013). In summary, Group Awareness Tools enhanced students' awareness of group interaction and peers' knowledge, helped decrease off-task behaviors and stimulate participation and productive interaction, and helped identify free riders in the group (Janssen et al., 2007). It has proved to be a fruitful tool in online learning contexts.

Visual Representation Tools seemed to be the second most effective tools. When students collaboratively constructed visual representations, they performed better than those without access to such tools, as illustrated by the $E S$ of 0.54 for knowledge gain and 0.83 for group task performance. The large effect for task performance can be explained by the fact that visual representations not only function as cognitive tools but also elicit group discourse in CL. As shared artifacts, they greatly promote consensus building and knowledge convergence, which may lead to successful completion of group tasks (Gijlers \& de Jong, 2013; Janssen et al., 2010). For knowledge gain, although the ES of this Visual Representation Tool is smaller than that of concept/knowledge mapping reported by Nesbit and Adesope (2006; $E S=0.82, d f=26$ ), the studies included in the present meta-analysis represent a quite different learning context. First, we only 
analyzed computer-based concept mapping, while Nesbit and Adesope included paper-and-pencil-based mapping. Second, concept/knowledge maps were constructed collaboratively in the studies included here, while Nesbit and Adesope did not distinguish between group and individual mapping. One possible explanation for the relatively small $E S$ is that the students did not have much experience of using such computer-based tools to create visual artifacts. In fact, learners may have difficulty using such tools (Van Drie, Van Boxtel, Jaspers, \& Kanselaar, 2005), and so they should be trained to use them to present their thoughts.

Virtual Environments also significantly improved learning outcomes. The synthesized results confirm the findings of a prior meta-analysis by Clark et al. (2016). In virtual learning environments, such as digital games, course content is integrated with collaborative game play, which helps students to increase their understanding of the subject matter (Lin et al., 2013; Y. T. C. Yang, 2015). Moreover, CL with digital games can gain the learners' attention and increase their interest and learning motivation.

Basic Online Discussion produced a medium ES for knowledge achievement. However, in non-FTF settings, Enhanced Online Discussion tools failed to reach significance on knowledge acquisition, and the effect was substantially smaller than that found by Jeong et al. (2016), who reported ESs of 0.48 and 0.40 for synchronous and asynchronous CSCL, respectively. It should be noted that Jeong et al. did not report independent $E S$ s for academic achievement, instead combining all outcomes.

Among the available studies on supporting strategies in CSCL, more (39 studies) were on Instruction and Guidance (mainly via collaboration scripts). This strategy appeared to be particularly promising. By receiving guidance and instruction on rules that specify and sequence interactions and activities, students would become more focused on deep discussion and task completion. Collaboration scripts or prompts facilitated elaboration, elicitation, and knowledge externalization, and sustained in-depth discussion, which in turn promoted high-level thinking and knowledge acquisition (Weinberger, Ertl, Fischer, \& Mandl, 2005).

Although Peer Feedback or Peer Assessment, Teacher's Facilitation, and Role Assignment are not unique to CSCL, technology use can facilitate their applications in CL. Web-based peer review of student writing proved to be beneficial. Giving peer reviews helped the students think more critically and acquire deeper understanding, and receiving reviews or feedback from peers helped them reflect on their own work and make further revisions and improvements (Trautmann, 2009; Xiao \& Lucking, 2008). The results for Teacher's Facilitation suggest that teachers or instructors should play the role of facilitator to improve student learning. Role Assignment raised student responsibility for group work, stimulated active participation and awareness of collaboration, and therefore improved student learning outcomes (Strijbos et al., 2004).

\section{Moderator Analysis of Research Design, Sample Size, and Duration}

Taking into consideration both the magnitude of ES and the $95 \%$ confidence interval, it seems that quasi-experimental studies produced significantly larger effects on knowledge gain by summing the included studies in Categories 1,2, and 3. In terms of the number of participants (i.e., sample size), it seems 
that studies with $<100$ participants reported better effects of interventions, while studies with $\geqslant 250$ participants produced small mean ESs. Research has shown that studies with small sample sizes generally report larger ESs than studies with large sample sizes (Slavin \& Smith, 2009).

With respect to intervention duration, larger mean ES may be found in any duration (i.e., $<1$ month, 1 month to 1 semester, $\geqslant 1$ semester). The relationships between duration and learning outcomes should thus be investigated in future research. CL might be only suitable for some specific learning content and, thus, may not be maintained over a full semester or full year. Note that in Category 1, among the studies reporting little or no positive effects, there were $13(50 \%)$ studies lasting for a short period of $<1$ month, 4 (18\%) studies of 1 month to 1 semester, and $3(12 \%)$ studies of $\geqslant 1$ semester, indicating that it is more possible that studies with shorter durations will have few or no positive effects (yet there is no such finding in Categories 2 and 3). This might be due to the fact that members of a group usually need some time to get familiar with one another and act as a productive team, especially in online distance learning (Fransen et al., 2013).

In addition, regarding the moderating effect of test type, there was significant variance between ESs for local tests and standardized tests in Category 1 but not in Categories 2 and 3. Due to the disparity in the numbers of sample studies (e.g., 66 vs. 6 in Category 1, 99 vs. 2 in Category 3) and relatively few studies with standardized tests, these results should be interpreted with caution. Studies using standardized tests can also achieve moderate effects, such as Genlott and Grönlund (2016). What is sure is that both types of tests led to significantly positive effects on knowledge achievement. The current research situation is that most empirical studies use local tests, as is the case in Lou et al.'s (2001) meta-analysis. It is also the case in the current meta-analysis, with only 19 out of more than 300 studies using standardized tests (6 studies in Category 1, 11 in Category 2, and 2 in Category 3 ). In addition, as mentioned above, the intervention duration might be several sessions or several weeks, and not necessarily a semester or a full academic year. In such conditions, there might be no fit or only loose fit standardized tests, and thus, local tests are more likely to align well with the instructional objectives. Another reason is that there generally only exist standardized tests for $\mathrm{K}-12$ literacy and mathematics courses and not for university courses. Besides, some studies were aimed at improving problem-solving skills, which might not be emphasized on standardized tests.

\section{Implications}

The implications of this meta-analysis are as follows. First, while the different elements of CSCL are investigated separately in individual research, they need to be integrated in CSCL practices. CSCL practices should consider collaboration activities (e.g., group task), computer support (e.g., discussion forum), and extra learning tools (e.g., Group Awareness Tools) or strategies (e.g., collaboration scripts) to facilitate CSCL.

Second, CSCL goes beyond simply providing students with computers, electronic textbooks, and discussion forums for CL; more often, it is critically important to incorporate specific learning systems, tools, or strategies to foster productive 
group interaction and achieve desirable outcomes. In this regard, educational practitioners have a great deal of flexibility, as there are various tools or strategies, such as interactive-oriented (e.g., videoconferencing), representation-oriented (e.g., concept mapping, Group Awareness Tools), and guiding-oriented (e.g., scripts) approaches.

Third, CSCL practices typically embed more than one technology tool in their environments, as using a single tool is often insufficient. Existing challenges in CSCL, such as off-task behaviors, free riders in the group, dominance issues, and superficial discourse, cannot be addressed by a single learning tool or strategy. This can be found by the research trend of studies in Category 3. For example, an environment might integrate scripts or prompts into a digital game environment.

Fourth, the selection of environments, tools, or strategies should align with the instructional goals, learners' needs, and the nature of the learning tasks. For example, in Y. T. C. Yang (2015), digital game-based learning fit well the instructional goal of developing employment-related knowledge and skills by providing authentic contexts for learning. Also, collaboration scripts provide scaffolds and guidance on how to sustain group discourse. An example for aligning task nature is the use of an argumentation map to facilitate the argument among group members.

Fifth, it is critically important for practitioners and researchers to design appropriate collaborative tasks. For example, the tasks presented to students should be complex enough to necessitate working in groups, that is, individual learners are not capable of successfully completing the task by themselves (F. Kirschner, Paas, \& Kirschner, 2011). Learners' expertise, prior knowledge, and/or experience should also be considered when designing collaborative tasks. What is complex for the novice might be only moderately complex for more experienced learners and simple for the expert (F. Kirschner et al., 2011).

Sixth, learners' lack of experience with CL and using relevant tools might make it difficult to fulfill the expected learning outcomes (Van Drie et al., 2005). Thus, it is necessary to train learners in technical and collaborative skills, which are viewed as prerequisites to effective CSCL.

Last, note that CSCL is not a panacea for all kinds of learning. It might be only suitable for some learning content and activities. Thus, in some empirical studies, CSCL was performed over a few weeks instead of being maintained over a full semester or a full year.

\section{Limitations}

This study is subject to several limitations. First, although some papers in other databases might meet the inclusion criteria but were not included in our analysis, the few studies would not have significantly affected the results due to the large number found in our literature search in the Web of Science. We also made efforts to address this possible limitation by a quick post hoc search using Google Scholar, the result of which suggested that very few new sources are available. Second, this meta-analysis does not report narrative descriptions of each study due to space limitations. Valuable information on each study could be found in the Supplemental Material titled "The Lists of the Analyzed Studies for the Three Categories" (available in the online version of the journal). In this Supplemental 
Material, a number of the empirical studies not included in the reference list can be found. Third, the moderators analyzed in this study were research design, sample size, duration, and test type, but other factors such as task complexity may also influence the variance in the effect sizes. Due to the space limitation, we did not conduct a homogeneity analysis to look into the effects of other contextual variables. Fourth, this study aggregated empirical studies on limited types of learning tools or supporting strategies, leaving more uncovered due to the small number of studies using such tools. For example, mobile learning and some social network tools (e.g., Facebook $\left.{ }^{\circledR}\right)$ have been gaining research attention in recent years, some of which have been reflected by our meta-analysis. However, due to the small number of studies, their findings are not synthesized here. Note that more detailed elaboration of the principles of CSCL practice is not within the scope of this meta-analysis, as this area deserves a future systematic review.

\section{Methodological and Practical Issues in Existing CSCL Empirical Studies}

Some issues in the existing empirical studies are pinpointed as follows. First, there were studies that did not ensure the equivalence of prior knowledge between the experimental and control conditions before the experiment. A significant difference in the prior knowledge can make it hard to interpret to what extent the effects were from the intervention.

Second, there was a lack of careful design of collaborative tasks. Some studies merely asked students to sit together using one computer to learn concepts or post a minimal number of messages or share information in a forum. In some other studies, learners were presented with CL tasks and activities that they could more efficiently carry out individually, leading to minimal collaboration; the task itself could not motivate students to engage in productive collaboration (F. Kirschner et al., 2011).

Third, it is observed that a few studies involved quite a small sample size (e.g., less than 30 experiment participants, or even 2 or 3 student groups in each condition), resulting in large variance in their results (e.g., Lin et al., 2016). This may trigger a doubt about their results. Some other studies had short (e.g., $<2$ hours) interventions, which might result in little or no effect on learning, especially for online or remote learning settings, as learners of online distance learning usually do not know one another and need time to get familiar with peers in order to form a well-functioning team (P. A. Kirschner \& Erkens, 2013).

Fourth, regarding the measure of social interaction, some studies just counted the number of messages posted on a discussion forum, failing to capture the dynamics and quality of group discourse. Additionally, there were relatively few studies concerned with the measure of skills such as problem solving, which are also desirable outcomes of CSCL.

\section{Conclusion}

Research on CSCL explores the use of ICTs or computer-based technologies to support CL by facilitating group processes and knowledge co-construction. The literature reveals that CSCL is a learning situation involving multiple elements such as collaboration in learning processes, computer support for CL, and the incorporation of extra learning environments or tools, and/or supporting strategies 
to facilitate CSCL. Empirical studies examine the effects of CSCL in multiple measures concerning individual knowledge gains, individual skill acquisition, individual perceptions, group task performance, and social interaction. Based on the results of 425 empirical studies, all three elements have produced favorable effects.

First, collaboration had significant positive effects on knowledge gain $(E S=0.42)$, skill acquisition $(E S=0.64)$, and student perception $(E S=0.38)$ in computer-based learning settings by stimulating students to discuss their understandings with peers, explain and elaborate their ideas to others, reflect on peers' feedback, learn from others, and come up with problem solutions that might not have been possible alone. Second, computer use led to positive effects on knowledge gain $(E S=0.45)$, skill acquisition $(E S=0.53)$, student perception $(E S=0.51)$, group task performance $(E S=0.89)$, and social interaction $(E S=0.57)$ in CL contexts. Computer technology creates interactive and engaging learning environments, allows flexible time for students to interact with peers and reflect on their discourse, and fosters durable and equal communication. Third, the use of extra learning environments or tools produced a medium $E S$ for knowledge gain $(E S=0.55)$, and supporting strategies resulted in an $E S$ of 0.38 for knowledge gain. They also led to significant positive effects on skill acquisition, student perceptions, group task performance, and social interaction. Significant difference existed across different learning environments, tools, and strategies. Among them, Group Awareness Tools, Visual Representation Tools, and collaboration scripts appeared to be especially promising. Fourth, moderator analyses indicate that studies with quasiexperimental design and less than 100 participants produced larger effects on knowledge gain, while results on intervention duration and test type were inconclusive between the three categories of study.

Hopefully, the findings of the study may contribute to a deeper understanding of CSCL. The meta-analysis results have shown positive roles of CSCL in improving learning outcomes and processes in multiple measures. More importantly, the results reveal the effects of CSCL as a result of CL, computer use, and extra learning environments or tools, or supporting strategies. The findings may inform education researchers and practitioners regarding how CSCL can improve learning via including collaboration in computer-based learning environments, using computers to support collaboration and interaction during learning, and incorporating extra learning tools or strategies to facilitate CSCL. In particular, this study goes deep into synthesizing the kinds of technologies or strategies being commonly deployed and their affordances and highlighting their important characteristics. The fact that there were more studies exploring the effects of using extra learning environments or tools, or supporting strategies indicates that the focus of research in CSCL has shifted away from examining whether CS (i.e., computer support) or $\mathrm{CL}$ is effective to how extra technology tools or strategies can be used to improve the effects of CSCL by dealing with various challenges such as communication of complex ideas, superficial interaction, low awareness of social presence and peer contribution, inadequate sense of collective responsibility, inadequate guidance, and lack of feedback in CSCL settings. 


\section{Note}

This research was partially supported by the General Research Fund from the Research Grants Council of the Hong Kong SAR Government (Project No. 17201415). The authors thank Prof. Haijing Jiang for his valuable support for this study.

\section{ORCID iD}

M. Wang (iD) https://orcid.org/0000-0002-1084-6814

\section{References}

References marked with an asterisk indicate studies included in the meta-analysis.

Baker, M., Andriessen, J., Lund, K., Van Amelsvoort, M., \& Quignard, M. (2007). Rainbow: A framework for analysing computer-mediated pedagogical debates. International Journal of Computer-Supported Collaborative Learning, 2, 315-357. doi:10.1007/s11412-007-9022-4

*Benbunan-Fich, R., Hiltz, S. R., \& Turoff, M. (2002). A comparative content analysis of face-to-face vs. asynchronous group decision making. Decision Support Systems, 34, 457-469. doi:10.1016/S0167-9236(02)00072-6

Borokhovski, E., Bernard, R. M., Tamim, R. M., Schmid, R. F., \& Sokolovskaya, A. (2016). Technology-supported student interaction in post-secondary education: A meta-analysis of designed versus contextual treatments. Computers \& Education, 96, 15-28.

*Brewer, S., \& Klein, J. D. (2006). Type of positive interdependence and affiliation motive in an asynchronous, collaborative learning environment. Educational Technology Research and Development, 54, 331-354. doi:10.1007/s11423-0069603-3

Brusilovsky, P., \& Henze, N. (2007). Open corpus adaptive educational hypermedia. In P. Brusilovsky, A. Kobsa, \& W. Neidl (Eds.), The adaptive web: Methods and strategies of web personalization (pp. 671-696). Berlin, Germany: Springer.

*Buder, J., \& Bodemer, D. (2008). Supporting controversial CSCL discussions with augmented group awareness tools. International Journal of Computer-Supported Collaborative Learning, 3, 123-139. doi:10.1007/s11412-008-9037-5

*Chen, C. M., \& Chen, F. Y. (2014). Enhancing digital reading performance with a collaborative reading annotation system. Computers \& Education, 77, 67-81. doi:10.1016/j.compedu.2014.04.010

Chen, J., Wang, M., Grotzer, T. A., \& Dede, C. (2018). Using a three-dimensional thinking graph to support inquiry learning. Journal of Research in Science Teaching. Advance online publication. doi:10.1002/tea.21450

Cheng, B., Wang, M., \& Mercer, N. (2014). Effects of role assignment in concept mapping mediated small group learning. The Internet and Higher Education, 23, 27-38.

Clark, D. B., Tanner-Smith, E. E., \& Killingsworth, S. S. (2016). Digital games, design, and learning: A systematic review and meta-analysis. Review of Educational Research, 86, 79-122. doi:10.3102/0034654315582065

Cohen, J. (1992). Statistical power analysis. Current Directions in Psychological Science, 1(3), 98-101.

Cooper, H., Hedges, L. V., \& Valentine, J. C. (2009). The handbook of research synthesis and meta-analysis (2nd ed.). New York, NY: Russell Sage Foundation. 
*Corter, J. E., Esche, S. K., Chassapis, C., Ma, J., \& Nickerson, J. V. (2011). Process and learning outcomes from remotely-operated, simulated, and hands-on student laboratories. Computers \& Education, 57, 2054-2067. doi:10.1016/j. compedu.2011.04.009

Dede, C. (2009). Immersive interfaces for engagement and learning. Science, 323(5910), 66-69.

*Dehler, J., Bodemer, D., Buder, J., \& Hesse, F. W. (2011). Guiding knowledge communication in CSCL via group knowledge awareness. Computers in Human Behavior, 27, 1068-1078. doi:10.1016/j.chb.2010.05.018

Dillenbourg, P. (1999). What do you mean by collaborative learning. In P. Dillenbourg (Ed.), Collaborative-learning: Cognitive and computational approaches (pp. 1-19). Oxford, England: Elsevier.

Dillenbourg, P., \& Hong, F. (2008). The mechanics of CSCL macro scripts. International Journal of Computer-Supported Collaborative Learning, 3(1), 5-23.

Festinger, L. (1954). A theory of social comparison processes. Human Relations, 7, $117-140$.

*Fischer, F., \& Mandl, H. (2005). Knowledge convergence in computer-supported collaborative learning: The role of external representation tools. Journal of the Learning Sciences, 14, 405-441. doi:10.1207/s15327809j1s1403_3

*Frailich, M., Kesner, M., \& Hofstein, A. (2009). Enhancing students' understanding of the concept of chemical bonding by using activities provided on an interactive website. Journal of Research in Science Teaching, 46, 289-310. doi:10.1002/ tea. 20278

Fransen, J., Weinberger, A., \& Kirschner, P. A. (2013). Team effectiveness and team development in CSCL. Educational Psychologist, 48(1), 9-24. doi:10.1080/00461 520.2012 .747947

*Genlott, A. A., \& Grönlund, Å. (2016). Closing the gaps: Improving literacy and mathematics by ICT-enhanced collaboration. Computers \& Education, 99, 68-80. doi:10.1016/j.compedu.2016.04.004

*Gielen, M., \& De Wever, B. (2015). Structuring peer assessment: Comparing the impact of the degree of structure on peer feedback content. Computers in Human Behavior, 52, 315-325. doi:10.1016/j.chb.2015.06.019

*Gijlers, H., \& de Jong, T. (2013). Using concept maps to facilitate collaborative simulation-based inquiry learning. Journal of the Learning Sciences, 22, 340-374. doi: 10.1080/10508406.2012.748664

Hale, K. S., \& Stanney, K. M. (2014). Handbook of virtual environments: Design, implementation, and applications. Mahwah, NJ: Lawrence Erlbaum.

Hare, A. P. (1994). Types of roles in small groups: A bit of history and a current perspective. Small Group Research, 25, 433-448. doi:10.1177/1046496494253005

Hattie, J., \& Timperley, H. (2007). The power of feedback. Review of Educational Research, 77, 81-112. doi:10.3102/003465430298487

Hedges, L. V., \& Vevea, J. L. (1998). Fixed- and random-effects models in metaanalysis. Psychological Methods, 3, 486-504.

*Hoic-Bozic, N., Holenko Dlab, M., \& Mornar, V. (2016). Recommender system and Web 2.0 tools to enhance a blended learning model. IEEE Transactions on Education, 59(1), 39-44. doi:10.1109/TE.2015.2427116

Hovardas, T., Tsivitanidou, O. E., \& Zacharia, Z. C. (2014). Peer versus expert feedback: An investigation of the quality of peer feedback among secondary school students. Computers \& Education, 71, 133-152. doi:10.1016/j.compedu.2013.09.019 


\section{Chen et al.}

Hsiao, H. S., Chang, C. S., Lin, C. Y., Chang, C. C., \& Chen, J. C. (2014). The influence of collaborative learning games within different devices on student's learning performance and behaviours. Australasian Journal of Educational Technology, 30, 652-669.

*Hsieh, Y. H., \& Tsai, C. C. (2012). The effect of moderator's facilitative strategies on online synchronous discussions. Computers in Human Behavior, 28, 1708-1716. doi:10.1016/j.chb.2012.04.010

*Huang, Y. M., \& Liu, C. H. (2009). Applying adaptive swarm intelligence technology with structuration in web-based collaborative learning. Computers \& Education, 52, 789-799. doi:10.1016/j.compedu.2008.12.002

*Hwang, W. Y., \& Hu, S. S. (2013). Analysis of peer learning behaviors using multiple representations in virtual reality and their impacts on geometry problem solving. Computers \& Education, 62, 308-319. doi:10.1016/j.compedu.2012.10.005

Janssen, J., \& Bodemer, D. (2013). Coordinated computer-supported collaborative learning: Awareness and awareness tools. Educational Psychologist, 48(1), 40-55.

*Janssen, J., Erkens, G., Kanselaar, G., \& Jaspers, J. (2007). Visualization of participation: Does it contribute to successful computer-supported collaborative learning? Computers \& Education, 49, 1037-1065. doi:10.1016/j.compedu.2006.01.004

*Janssen, J., Erkens, G., Kirschner, P. A., \& Kanselaar, G. (2010). Effects of representational guidance during computer-supported collaborative learning. Instructional Science, 38(1), 59-88. doi:10.1007/s11251-008-9078-1

Jeong, H., Hmelo-Silver, C. E., Jo, K., \& Shin, M. (2016, January). CSCL in STEM education: Preliminary findings from a meta-analysis. Paper presented at the Proceedings of the 49th Hawaii International Conference on System Sciences (HICSS), Hawaii.

Jeong, H., Hmelo-Silver, C. E., \& Yu, Y. (2014). An examination of CSCL methodological practices and the influence of theoretical frameworks 2005-2009. International Journal of Computer-Supported Collaborative Learning, 9, 305-334. doi:10.1007/s11412-014-9198-3

*Ke, F. (2008). Alternative goal structures for computer game-based learning. International Journal of Computer-Supported Collaborative Learning, 3, 429-445. doi:10.1007/s11412-008-9048-2

Kirschner, F., Paas, F., \& Kirschner, P. A. (2011). Task complexity as a driver for collaborative learning efficiency: The collective working-memory effect. Applied Cognitive Psychology, 25, 615-624. doi:10.1002/acp.1730

Kirschner, P. A. (2001). Using integrated electronic environments for collaborative teaching/learning. Learning and Instruction, 10(Suppl. 1), 1-9.

Kirschner, P. A., \& Erkens, G. (2013). Toward a framework for CSCL research. Educational Psychologist, 48, 1-8. doi:10.1080/00461520.2012.750227

Kirschner, P. A., Kirschner, F., \& Janssen, J. (2014). The collaboration principle in multimedia learning. In R. Mayer (Ed.), The Cambridge handbook of multimedia learning (2nd ed., pp. 547-575). New York, NY: Cambridge University Press.

Kirschner, P. A., Kreijns, K., \& Jochems, W. (2003). Measuring the perceived quality of social space in distributed learning groups. In B. Wasson, S. Ludvigsen, \& U. Hoppe (Eds.), Designing for change in networked learning environment (pp. 323332). Dordrecht, Netherlands: Kluwer Academic.

Kollar, I., Fischer, F., \& Hesse, F. W. (2006). Collaboration scripts: A conceptual analysis. Educational Psychology Review, 18, 159-185. doi:10.1007/s10648-0069007-2 
*Kolloffel, B., Eysink, T. H. S., \& de Jong, T. (2011). Comparing the effects of representational tools in collaborative and individual inquiry learning. International Journal of Computer-Supported Collaborative Learning, 6, 223-251. doi:10.1007/ s11412-011-9110-3

Kreijns, K., Kirschner, P. A., \& Jochems, W. (2003). Identifying the pitfalls for social interaction in computer-supported collaborative learning environments: A review of the research. Computers in Human Behavior, 19, 335-353. doi:10.1016/S07475632(02)00057-2

Kreijns, K., Kirschner, P. A., Jochems, W., \& Van Buuren, H. (2004). Determining sociability, social space, and social presence in (a)synchronous collaborative groups. Cyberpsychology and Behavior, 7, 155-172. doi:10.1089/109493104323024429

*Kwon, S. Y., \& Cifuentes, L. (2009). The comparative effect of individually-constructed vs. collaboratively-constructed computer-based concept maps. Computers \& Education, 52, 365-375. doi:10.1016/j.compedu.2008.09.012

Kyndt, E., Raes, E., Lismont, B., Timmers, F., Cascallar, E., \& Dochy, F. (2013). A meta-analysis of the effects of face-to-face cooperative learning. Do recent studies falsify or verify earlier findings? Educational Research Review, 10, 133-149.

*Lan, Y. J., Sung, Y. T., \& Chang, K. E. (2009). Let us read together: Development and evaluation of a computer-assisted reciprocal early English reading system. Computers \& Education, 53, 1188-1198. doi:10.1016/j.compedu.2009.06.002

*Lin, T. J., Duh, H. B. L., Li, N., Wang, H. Y., \& Tsai, C. C. (2013). An investigation of learners' collaborative knowledge construction performances and behavior patterns in an augmented reality simulation system. Computers \& Education, 68, 314 321. doi:10.1016/j.compedu.2013.05.011

*Lin, Y. T., Chang, C. H., Hou, H. T., \& Wu, K. C. (2016). Exploring the effects of employing Google Docs in collaborative concept mapping on achievement, concept representation, and attitudes. Interactive Learning Environments, 24, 1552-1573. doi:10.1080/10494820.2015.1041398

Lipsey, M. W., \& Wilson, D. B. (2001). Practical meta-analysis. Thousand Oaks, CA: Sage.

*Liu, T. Y., Tan, T. H., \& Chu, Y. L. (2009). Outdoor natural science learning with an RFID-supported immersive ubiquitous learning environment. Educational Technology \& Society, 12, 161-175.

Lou, Y., Abrami, P. C., \& D’Apollonia, S. (2001). Small group and individual learning with technology: A meta-analysis. Review of Educational Research, 71, 449-521.

Manouselis, N., Drachsler, H., Vuorikari, R., Hummel, H., \& Koper, R. (2011). Recommender systems in technology enhanced learning. In F. Ricci, L. Rokach, B. Shapira, \& P. B. Kantor (Eds.), Recommender systems handbook (pp. 387-415). Boston, MA: Springer.

*Mercier, E. M., \& Higgins, S. E. (2013). Collaborative learning with multi-touch technology: Developing adaptive expertise. Learning and Instruction, 25, 13-23.

*Michinov, N., \& Primois, C. (2005). Improving productivity and creativity in online groups through social comparison process: New evidence for asynchronous electronic brainstorming. Computers in Human Behavior, 21, 11-28. doi:10.1016/j. chb.2004.02.004

*Moreno, R. (2009). Constructing knowledge with an agent-based instructional program: A comparison of cooperative and individual meaning making. Learning and Instruction, 19, 433-444. doi:10.1016/j.learninstruc.2009.02.018 


\section{Chen et al.}

Morris, R., Hadwin, A. F., Gress, C. L. Z., Miller, M., Fior, M., Church, H., \& Winne, P. H. (2010). Designing roles, scripts, and prompts to support CSCL in gStudy. Computers in Human Behavior, 26, 815-824. doi:10.1016/j.chb.2008.12.001

Nesbit, J. C., \& Adesope, O. O. (2006). Learning with concept and knowledge maps: A meta-analysis. Review of Educational Research, 76, 413-448.

*Noroozi, O., Biemans, H. J. A., Weinberger, A., Mulder, M., \& Chizari, M. (2013). Scripting for construction of a transactive memory system in multidisciplinary CSCL environments. Learning and Instruction, 25, 1-12. doi:10.1016/j.learninstruc.2012.10.002

*Noroozi, O., Teasley, S. D., Biemans, H. J. A., Weinberger, A., \& Mulder, M. (2013). Facilitating learning in multidisciplinary groups with transactive CSCL scripts. International Journal of Computer-Supported Collaborative Learning, 8, 189-223. doi:10.1007/s11412-012-9162-Z

*Noroozi, O., Weinberger, A., Biemans, H. J. A., Mulder, M., \& Chizari, M. (2012). Argumentation-based computer supported collaborative learning (ABCSCL): A synthesis of 15 years of research. Educational Research Review, 7, 79-106. doi:10.1016/j.edurev.2011.11.006

Okita, S. Y., Turkay, S., Kim, M., \& Murai, Y. (2013). Learning by teaching with virtual peers and the effects of technological design choices on learning. Computers \& Education, 63, 176-196.

Pellegrino, J. W., \& Hilton, M. L. (2013). Education for life and work: Developing transferable knowledge and skills in the 21st century. Washington, DC: National Academies Press.

*Peterson, A. T., \& Roseth, C. J. (2015). Effects of four CSCL strategies for enhancing online discussion forums: Social interdependence, summarizing, scripts, and synchronicity. International Journal of Educational Research, 76, 147-161. doi:10.1016/j.ijer.2015.04.009

*Rebetez, C., Bétrancourt, M., Sangin, M., \& Dillenbourg, P. (2010). Learning from animation enabled by collaboration. Instructional Science, 38, 471-485. doi:10.1007/ s11251-009-9117-6

Resta, P., \& Laferrière, T. (2007). Technology in support of collaborative learning. Educational Psychology Review, 19(1), 65-83.

*Roseth, C. J., Saltarelli, A. J., \& Glass, C. R. (2011). Effects of face-to-face and computer-mediated constructive controversy on social interdependence, motivation, and achievement. Journal of Educational Psychology, 103, 804-820. doi:10.1037/ a0024213

Salomon, G., \& Perkins, D. N. (1998). Individual and social aspects of learning. Review of Research in Education, 23, 1-24.

*Saltarelli, A. J., \& Roseth, C. J. (2014). Effects of synchronicity and belongingness on face-to-face and computer-mediated constructive controversy. Journal of Educational Psychology, 106, 946-960. doi:10.1037/a0036898

Slavin, R. E., Lake, C., \& Groff, C. (2009). Effective programs in middle and high school mathematics: A best-evidence synthesis. Review of Educational Research, 79, 839-911.

Slavin, R. E., \& Smith, D. (2009). The relationship between sample sizes and effect sizes in systematic reviews in education. Educational Evaluation and Policy Analysis, 31, 500-506. doi:10.3102/0162373709352369 
*Smith, J., Wilson, S. B., Banks, J., Zhu, L., \& Varma-Nelson, P. (2014). Replicating peer-led team learning in cyberspace: Research, opportunities, and challenges. Journal of Research in Science Teaching, 51, 714-740. doi:10.1002/tea.21163

Springer, L., Stanne, M. E., \& Donovan, S. S. (1999). Effects of small-group learning on undergraduates in science, mathematics, engineering, and technology: A metaanalysis. Review of Educational Research, 69, 21-51.

Stahl, G. (2006). Group cognition: Computer support for building collaborative knowledge. Cambridge: MIT Press.

Stahl, G., Koschmann, T., \& Suthers, D. (2006). Computer-supported collaborative learning: An historical perspective. In R. K. Sawyer (Ed.), Cambridge handbook of the learning sciences (pp. 409-426). Cambridge, England: Cambridge University Press.

*Strijbos, J. W., Martens, R. L., Jochems, W. M. G., \& Broers, N. J. (2004). The effect of functional roles on group efficiency: Using multilevel modeling and content analysis to investigate computer-supported collaboration in small groups. Small Group Research, 35, 195-229.

Su, A. Y. S., Yang, S. J. H., Hwang, W. Y., \& Zhang, J. (2010). A Web 2.0-based collaborative annotation system for enhancing knowledge sharing in collaborative learning environments. Computers \& Education, 55, 752-766. doi:10.1016/j. compedu.2010.03.008

*Sung, H. Y., \& Hwang, G. J. (2013). A collaborative game-based learning approach to improving students' learning performance in science courses. Computers \& Education, 63, 43-51. doi:10.1016/j.compedu.2012.11.019

*Suthers, D. D., Vatrapu, R., Medina, R., Joseph, S., \& Dwyer, N. (2008). Beyond threaded discussion: Representational guidance in asynchronous collaborative learning environments. Computers \& Education, 50, 1103-1127. doi:10.1016/j. compedu.2006.10.007

Tanner-Smith, E. E., \& Tipton, E. (2014). Robust variance estimation with dependent effect sizes: Practical considerations including a software tutorial in Stata and SPSS. Research Synthesis Methods, 5(1), 13-30.

*Trautmann, N. M. (2009). Interactive learning through web-mediated peer review of student science reports. Educational Technology Research and Development, 57, 685-704. doi:10.1007/s11423-007-9077-y

Tsai, C. W. (2010). Do students need teacher's initiation in online collaborative learning? Computers \& Education, 54, 1137-1144. doi:10.1016/j.compedu.2009.10.021

*Tsai, C. W. (2013). An effective online teaching method: The combination of collaborative learning with initiation and self-regulation learning with feedback. Behaviour and Information Technology, 32, 712-723.

*Tsaushu, M., Tal, T., Sagy, O., Kali, Y., Gepstein, S., \& Zilberstein, D. (2012). Peer learning and support of technology in an undergraduate biology course to enhance deep learning. CBE Life Sciences Education, 11, 402-412. doi:10.1187/cbe.12-040042

*Tsuei, M. (2011). Development of a peer-assisted learning strategy in computer-supported collaborative learning environments for elementary school students. British Journal of Educational Technology, 42, 214-232. doi:10.1111/j.1467-8535. 2009.01006.x

*Van Drie, J., Van Boxtel, C., Jaspers, J., \& Kanselaar, G. (2005). Effects of representational guidance on domain specific reasoning in CSCL. Computers in Human Behavior, 21, 575-602. doi:10.1016/j.chb.2004.10.024 


\section{Chen et al.}

Vogel, F., Wecker, C., Kollar, I., \& Fischer, F. (2017). Socio-cognitive scaffolding with computer-supported collaboration scripts: A meta-analysis. Educational Psychology Review, 29, 477-511.

Wang, M., Cheng, B., Chen, J., Mercer, N., \& Kirschner, P. A. (2017). The use of webbased collaborative concept mapping to support group learning and interaction in an online environment. Internet and Higher Education, 34, 28-40. doi:10.1016/j.iheduc.2017.04.003

Wang, M., Yuan, B., Kirschner, P. A., Kushniruk, A. W., \& Peng, J. (2018). Reflective learning with complex problems in a visualization-based learning environment with expert support. Computers in Human Behavior, 87, 406-415. doi:10.1016/j. chb.2018.01.025

Wecker, C., \& Fischer, F. (2014). Where is the evidence? A meta-analysis on the role of argumentation for the acquisition of domain-specific knowledge in computersupported collaborative learning. Computers \& Education, 75, 218-228.

*Weinberger, A., Ertl, B., Fischer, F., \& Mandl, H. (2005). Epistemic and social scripts in computer-supported collaborative learning. Instructional Science, 33, 1-30. doi:10.1007/s11251-004-2322-4

Weinberger, A., \& Fischer, F. (2006). A framework to analyze argumentative knowledge construction in computer-supported collaborative learning. Computers \& Education, 46, 71-95.

*Weinberger, A., Stegmann, K., \& Fischer, F. (2010). Learning to argue online: Scripted groups surpass individuals (unscripted groups do not). Computers in Human Behavior, 26, 506-515.

*Workman, M. (2004). Performance and perceived effectiveness in computer-based and computer-aided education: Do cognitive styles make a difference? Computers in Human Behavior, 20, 517-534. doi:10.1016/j.chb.2003.10.003

Wu, B., \& Wang, M. (2012). Integrating problem solving and knowledge construction through dual mapping. Knowledge Management \& E-Learning, 4, 248-257.

*Xiao, Y., \& Lucking, R. (2008). The impact of two types of peer assessment on students' performance and satisfaction within a Wiki environment. Internet and Higher Education, 11, 186-193. doi:10.1016/j.iheduc.2008.06.005

*Yang, K. Y., \& Heh, J. S. (2007). The impact of internet virtual physics laboratory instruction on the achievement in physics, science process skills and computer attitudes of 10th-grade students. Journal of Science Education and Technology, 16, 451-461. doi:10.1007/s10956-007-9062-6

*Yang, Y. T. C. (2015). Virtual CEOs: A blended approach to digital gaming for enhancing higher order thinking and academic achievement among vocational high school students. Computers \& Education, 81, 281-295. doi:10.1016/j.compedu.2014.10.004

Yu, F. Y. (2001). Competition within computer-assisted cooperative learning environments: Cognitive, affective, and social outcomes. Journal of Educational Computing Research, 24, 99-117. doi:10.2190/3U7R-DCD5-F6T1-QKRJ

\section{Authors}

JUANJUAN CHEN is doctoral student in the Laboratory for Knowledge Management \& E-Learning (KM\&EL) in the Faculty of Education, The University of Hong Kong, Pokfulam Road, Hong Kong; email: jjchen12@connect.hku.hk. She received her master's degree in electronics and communication engineering from Tsinghua University. 
Her research interests focus on computer-supported collaborative learning, visual representation, cognitive mapping, science education, inquiry learning, and technologyenhanced learning environments.

MINHONG WANG is an associate professor and director of the Laboratory for Knowledge Management \& E-Learning (KM\&EL) in the Faculty of Education, The University of Hong Kong, Pokfulam Road, Hong Kong; email: magwang@hku.hk. She is an Eastern Scholar Chair Professor at East China Normal University. She serves as the editor-inchief of Knowledge Management \& E-Learning and as associate editor of Information \& Management. She was a guest editor of Computers in Human Behavior and Educational Technology \& Society. She has published widely on technology-enhanced learning, problem solving and inquiry learning, creative thinking and collaboration, and medical education. Her recent monograph is E-Learning in the Workplace: $A$ Performance-Oriented Approach Beyond Technology. Correspondence concerning this article should be addressed to Minhong (Maggie) Wang.

PAUL A. KIRSCHNER, dr.h.c. (1951), is Distinguished University Professor and professor of educational psychology at the Open University of the Netherlands, Valkenburgerweg 177, Heerlen 6419AT, Netherlands; email: paul.kirschner@ou.nl. $\mathrm{He}$ is also a visiting professor of education with a special emphasis on Learning and Interaction in Teacher Education at the University of Oulu, Finland. He is a research fellow of the American Educational Research Association, the International Society of the Learning Sciences, and the Netherlands Institute for Advanced Study in the Humanities and Social Science. He is a past president (2010-2011) of the International Society of the Learning Sciences and a former member of the Dutch Educational Council and, as such, was advisor to the Minister of Education (2000-2004). He is also a member of the Scientific Technical Council of the Foundation for University Computing Facilities (SURF WTR), chief editor of Journal of Computer Assisted Learning and associate editor of Computers in Human Behavior. He is coauthor of the recently released book Urban Myths About Learning and Education as well as of the highly successful book Ten Steps to Complex Learning, and editor of two other books (Visualizing Argumentation and What We Know About CSCL).

CHIN-CHUNG TSAI holds a BSc in physics from National Taiwan Normal University. He received a master of education degree from Harvard University and completed his doctoral study at Teachers College, Columbia University, in 1996. From 1996 to 2006, he was in the faculty of Center for Teacher Education and Institute of Education, National Chiao Tung University, Hsinchu, Taiwan. He was a Chair Professor at the Graduate Institute of Digital Learning and Education, National Taiwan University of Science and Technology, Taipei, Taiwan, from 2006 to 2017. He is currently a Chair Professor and Head for Program of Learning Sciences, National Taiwan Normal University, No. 162, Sec. 1, He-Ping E. Road, Taipei, Taiwan. He is also affiliated with the Institute for Research Excellence in Learning Sciences, National Taiwan Normal University. Since July 2009, he has been appointed as the coeditor of Computers \& Education. He is also currently serving as the editor of International Journal of Science Education. His research interests deal largely with constructivism, epistemic beliefs, and Internet-based instruction. 